\title{
Mudança climática e desenvolvimento humano: uma análise baseada na Abordagem das Capacitações de Amartya Sen
}

\section{Climate change and human development: an analysis based on Amartya Sen's Capability Approach}

\author{
Esmeralda Correa-Macana* \\ Flávio CoMim**
}

\begin{abstract}
The objective of this article is to explore the impacts of climate change on human development from Sen's Capability perspective. Its main contribution lies in the analytical structure that it offers articulating well-being dimensions such as health, education, security, livelihoods, cultural values and social relation with natural resources, i.e., water, soil and biodiversity and ecosystem services. The analysis shows how climate change may increase human deprivation all over the world, with disproportionate effects on poor and developing countries.
\end{abstract}

Keywords: climate change, capability approach, human development and ecosystem services.

\section{Resumo}

O objetivo desse artigo é analisar os impactos da mudança climática sobre o desenvolvimento humano a partir da Abordagem das Capacitaçôes de Sen. A sua principal contribuição reside na estrutura analítica que oferece para a articulação de dimensóes relevantes ao bem-estar humano, como saúde, educação, segurança, meios de subsistência, valores culturais e relaçôes sociais em relação a recursos naturais como água, solo e biodiversidade, assim como os serviços dos ecossistemas. A análise demonstra como as alteraçóes do clima podem aumentar as privações humanas em todo o mundo, com desproporcionais efeitos em países pobres e em desenvolvimento.

Palavras chaves: mudança climática, bem-estar humano, serviços dos ecossistemas, saúde, segurança e meios de subsistência.

* Pontifícia Universidade Católica do Rio Grande do Sul. Correo-e: esmeralda_cm13@hotmail. com, esmeralda.macana@pucrs.br

** Universidade de Cambridge. Correo-e: fvc1001@cam.ac.uk 


\section{Introdução}

A principal entidade avaliadora do conhecimento sobre alterações climáticas, o Painel Intergovernamental de Mudança Climática (International Panel on Climate Change, IPCC), conclui em seu último relatório que as recentes mudanças do clima atribuídas ao aquecimento da terra têm afetado os sistemas físicos e biológicos do planeta, assim como os sistemas naturais e humanos. As evidências distinguem impactos sobre os recursos hídricos, a produção agrícola, a biodiversidade, zonas costeiras e sobre a saúde das pessoas (IPCC, 2007a). A análise apresentada neste artigo contribui ao entendimento de como esses eventos podem influenciar no processo de desenvolvimento humano.

No último século, a temperatura média da superfície aumentou $0,7^{\circ} \mathrm{C}^{1}$ e o nível médio do mar elevou-se $0,17 \mathrm{~m}$. Tem-se observado maior taxa de derretimento das camadas de gelo e aumento de precipitaçóes e evaporação nos oceanos. Desde 1970, tem aumentado a freqüência e intensidade de eventos extremos como secas, inundaçóes e tempestades de vento (IPCC, 2007b).

De acordo com os cenários projetados pelo IPCC (2007b), a temperatura média global deve aumentar entre $2,3^{\circ} \mathrm{C}$ e $4,5^{\circ} \mathrm{C}$ para o ano de 2100 (relativo ao período pré-industrial). ${ }^{2}$ Além disso, não se descarta a possibilidade de elevaçôes superiores a $4,5^{\circ} \mathrm{C}$. Tendo em conta o maior aquecimento da terra e das águas dos oceanos, estima-se que haja influência sobre fenômenos naturais responsáveis pela estabilidade do clima regional, como, por exemplo, El Niño ${ }^{3}$ e La Niña, associados com períodos de secas e inundaçóes na regiâo dos trópicos (IPCC, 2007b).

Parte da preocupação com a mudança climática é de que ela ultrapasse os limites de resistência dos sistemas naturais, dentro dos quais parti-

${ }^{1}$ Refere-se a graus Celsius.

${ }^{2}$ Refere-se à temperatura média no período de 1861-1890.

${ }^{3} \mathrm{O}$ oceano representa um dos principais componente do sistema climático. O papel dele na estabilidade do clima relaciona-se com o acoplamento de energia entre o oceano e a atmosfera, a partir do qual, originam-se os eventos naturais internos que determinam o clima regional, denominados como El Niño Oscilação Sul (ENOs), "Pacific Decadal Oscillation" (PDO), o "Northern Annular Mode" (NAM) e a Oscilação do Atlântico Norte (OAN). Com respeito ao significado do ENOS, a Oscilação Sul refere-se ao componente da atmosfera, enquanto El Niño corresponde ao componente do oceano, desta forma, o acoplamento entre os dois componentes (atmosfera e oceano) dá origem a El Niño Oscilação Sul ENOS (IPCC, 2007b). Eventuais alteraçốes nas propriedades físicas e químicas dos oceanos, por causa do maior armazenamento de calor e aumentos de salinidade, podem produzir mudanças no clima dentro de uma escala de tempo estacional, decenal e de séculos, assim como em uma escala espacial global e regional. De igual forma, devido ao aquecimento e elevaçôes do nível do mar, existe a possibilidade de aumentar a freqüência e magnitude com que ocorrem os fenômenos naturais ENOS, PDO, NAM e OAN, levando à instabilidade do clima regional. Assim por exemplo, o fenômeno de El Niño é o responsável dos intensos períodos de seca e em seu processo contrário, La Niña, das inundações na região dos trópicos (IPCC, 2007b). 
cipa o homem. Segundo o Programa das Naçóes Unidas para o Desenvolvimento (PNUD, 2007), o consenso científico define a fronteira para distinguir entre as alterações climáticas seguras e as perigosas, apontando um máximo razoável de $2^{\circ} \mathrm{C}$ no aumento da temperatura (relativo ao período pré-industrial). Acima desse limite, os riscos climáticos podem ser catastróficos. O nível do mar pode aumentar em um metro, suficiente para submergir $12 \%$ do território das Bahamas e 10\% do território do Vietná. A pressão que isso exerceria sobre as zonas costeiras poderia afetar cerca de 56 milhóes de pessoas de países em desenvolvimento (Dasgupta et al., 2007). Poderia também dar inicio ao colapso da floresta Amazônica e colocar em perigo de extinção de 20 a 50\% das espécies no Sul da África (Stern, 2007).

A mudança climática representa um problema para a humanidade de conotaçóes complexas. Por um lado, os Gases de Efeito Estufa (GEE), responsáveis pelo desequilíbrio do sistema climático, distinguem-se por serem acumulativos e irreversíveis, permanecendo dentro da atmosfera por séculos e sendo capazes de intensificar processos que podem durar por muitas geraçóes. Em conseqüência, os impactos dos GEE devem ser tolerados ao longo do tempo (Stern, 2007).

Por outro lado, a mudança climática caracteriza-se por ser de abrangência global, tanto em suas causas como em suas conseqüências (IPCC, 2007b). A atmosfera faz com que exista interdependência ecológica entre as regiōes do mundo (PNUD, 2007). Dessa forma, os efeitos dos GEE emitidos nos Estados Unidos podem ser sentidos nos países da África ou da América Latina, e vice-versa.

A mudança climática, ainda sendo uma problemática de escala global, manifesta um conjunto de desigualdades entre as regiōes do mundo (Stern, 2007). Em primeiro lugar, há diferenças no volume de emissão de GEE entre os países, para o qual, as evidências designam maior responsabilidade para os países ricos. Pode-se destacar que atualmente estas desigualdades são marcadas pelos padróes de produção e de consumo dos indivíduos, com pessoas de países ricos exercendo maior pressão sobre os ecossistemas do que pessoas de países pobres (Abramovay, 2010). Em segundo lugar, há desigualdade na distribuição dos impactos das alteraçóes climáticas, pois eles surgem em proporçôes diferentes e por eventos climáticos distintos para cada país. Além disso, os impactos são diferenciados porque as perturbaçóes climáticas interagem com fatores de vulnerabilidade pré-existente de cada país, relacionados à exposição devida à localização geográfica, grau de dependência da economia das atividades agrícolas e funcionamento dos serviços dos ecossistemas e capacidade de adaptação definida por aspectos sociais, econômicos, institucionais, políticos e dotação dos recursos naturais. 
Apesar do fenômeno da mudança climática não ser explicado meramente pela renda, são os países pobres os que devem enfrentar os maiores riscos, embora não sejam responsáveis pela maior parcela de emissão de GEE. Estes países são mais vulneráveis por estarem localizados em regióes mais quentes e de maior exposição a eventos extremos, por dependerem mais da agricultura e dos ecossistemas e por sua restrita capacidade de ajustamento.

Em termos de bem estar humano, a mudança climática representa uma ameaça superior a qualquer outra mudança ambiental. Isso se deve a seu caráter irreversível, a sua escala espacial global e a sua combinação com fatores sociais e ecológicos que fazem com que seus fenômenos possam ocorrer de maneira incerta, difícil de prever, pois os impactos refletem uma multitude de complexidades.

Por isso argumenta-se que os impactos da mudança climática sobre o desenvolvimento humano podem ser múltiplos e complexos. No entanto, são poucos os estudos que levantam uma discussão nessa linha, especificamente focada na interação entre as duas áreas. Em especial, têm sido pouco exploradas a caracterização e sistematização de impactos no bemestar humano a partir de uma ótica multidimensional, ou seja, em relação aos diferentes funcionamentos de realizações e açóes que são valoradas pelas pessoas, como a saúde, a segurança, a educação e os meios de subsistência. Nessas análises, é interessante destacar uma abordagem de desenvolvimento humano que considere aspectos que váo além de julgamentos relacionados à renda ou commodities disponíveis pelos indivíduos, pois estes aspectos não são suficientes para explicar o bem-estar humano quando, por exemplo, a qualidade do ar é reduzida ou quando as pessoas se deparam com eventos extremos do clima.

Dessa forma, o presente artigo visa explorar os elos entre a mudança climática e o desenvolvimento humano. Propóe assim uma estrutura analítica para identificar mecanismos de conexão entre as duas dimensôes, com a qual busca caracterizar e sistematizar os impactos sobre componentes do bem-estar humano.

Esta análise baseia-se na visão de desenvolvimento humano fundamentada por Amartya Sen através da Abordagem das Capacitaçóes. ${ }^{4}$ Tendo em conta esta abordagem, é possível avaliar as diversas formas em que as pessoas dependem do sistema climático e dos recursos naturais para viver, bem como as oportunidades que estes oferecem para expandir as capacitaçóes dos indivíduos.

${ }^{4}$ A palavra capability compreende tanto capacity quanto ability. Portanto, refere-se à habilidade dos indivíduos de ampliar suas capacidades. A palavra capability nâo deve ser traduzida como capacidade, pois esta ignora o elemento de autonomia que aparece con o uso da expressão de habilidade que os indivíduos possuem para formar e escolher suas próprias capacidades. 
O artigo está estruturado em cinco seções, incluindo esta introdução. A segunda seção apresenta a definição de mudança climática. A terceira seção examina a visão de desenvolvimento humano fundamentada pela Abordagem das Capacitaçóes de Amartya Sen. Nessa mesma seção, discute-se a estrutura analítica utilizada na caracterização e sistematização de impactos. A quarta seção mostra as evidências de impactos sobre os recursos naturais como água, solo e biodiversidade, assim como os efeitos sobre seus respectivos serviços dos ecossistemas, os quais representam os mecanismos associativos estabelecidos na estrutura analítica e através dos quais a mudança climática influencia de forma indireta o bem-estar humano. Na quinta seção é apresentada a análise de impactos sobre elementos do bem-estar humano, tais como: saúde, educação, segurança, meios de subsistência, valores culturais e relações sociais. Por último são apresentadas as conclusões.

\section{Em que consiste a mudança climática?}

O conceito de mudança climática faz referência às alteraçóes do clima através do tempo. De acordo com o IPCC (2007b), as mudanças do clima estão associadas tanto à variabilidade natural quanto à variabilidade originada como conseqüência das atividades do homem (razóes antropogênicas).

O sistema climático atua dentro de um complexo funcional interligado, composto por elementos como a superfície da terra, os oceanos e águas, camadas de gelo e neve, a atmosfera e corpos viventes (IPCC, 2007b). Esses elementos interagem através de processos naturais como o balanceamento entre a atmosfera e os oceanos, o efeito estufa, os processos de evaporaçáo, entre outros. Isto com a finalidade de manter o equilíbrio entre a energia que é recebida pelo sol e posteriormente sua liberação no espaço, sendo a condição necessária para conservar a estabilidade do clima. Por exemplo, o efeito estufa é uma característica natural necessária para manter a terra aquecida, se não fosse assim, a terra seria demasiado fria, dificultando a existência de vida nela (Stern, 2007). Porém, a problemática surge quando se estimula externamente esse processo e pressiona-se a um aquecimento maior ao gerado naturalmente. Portanto, qualquer desequilíbrio causado por fatores externos dentro dos processos e componentes que interferem no sistema climático e seu balanceamento de energia deve produzir alteraçóes climáticas, as quais podem se manifestar através das mudanças da temperatura, de precipitaçôes, umidade, aumento de eventos extremos e uma série de outros efeitos de realimentação (feedback), ou seja, efeitos que podem induzir a outro tipo de reaçóes ao interagir com outros elementos do ambiente. 
De acordo com a última publicação do IPCC (2007a), há maior certeza hoje, comparada com relatórios anteriores, que os aumentos de temperatura e as variaçóes do clima, são provavelmente causados por emissóes antropogênicas de GEE. De igual forma, na referida publicação são associadas às atividades do homem, com alta probabilidade, os aumentos da temperatura do mar, a perda de massa de gelo e padróes extremos dos ventos.

O desafio para as próximas décadas é enfrentar processos mais acelerados de alteração em todos os componentes do sistema climático. Nos últimos 50 anos, a temperatura média aumentou quase o dobro da taxa do último século $\left(0,13^{\circ} \mathrm{C}\right.$ e $0,7^{\circ} \mathrm{C}$, respectivamente) e os onze dos doze anos mais quentes desde 1850 encontram-se na década de 1995 a 2006. O nível do mar elevou-se a uma taxa média anual de $1,8 \mathrm{~mm}$ no período de 1961 a 2003, no entanto, a taxa foi mais acelerada entre 1993 e 2003, sendo de 3,1 mm por ano. A extensão média anual do gelo do mar Ártico tem diminuído em $2,7 \%$ por decênio, com maiores reduçóes durante o verão (de $7,4 \%$ por decênio). Desde 1970 , tem-se observado maior freqüência e intensidade de tempestades, precipitaçóes e secas. Se continuar o padrão atual de emissão de GEE, é muito provável que o aquecimento aumente e que as mudanças observadas em todos os componentes climáticos sejam significativas em 2100 (IPCC, 2007b).

\section{Abordagem do desenvolvimento humano}

A abordagem de Desenvolvimento Humano representa uma tentativa de colocar assuntos do bem-estar das pessoas no centro de discussóes sobre crescimento econômico, políticas sociais, investimentos em tecnologia e em todos os aspectos relacionados com o desenvolvimento, inclusive no que se refere às questôes sobre o meio ambiente (Bagolin, 2005; Anand e Sen, 2000).

Nesse sentido, autores como Amartya Sen fundamentam a visão de desenvolvimento humano através da Abordagem das Capacitaçóes (AC). Segundo este autor, o desenvolvimento humano está associado com o aumento do potencial humano e com um "processo de expansão das liberdades reais que as pessoas desfrutam" (Sen, 2000: 52). Isto significa a ampliação das escolhas e oportunidades para as pessoas levarem o tipo de vida que valorizam a partir do que elas podem ser e fazer. As pessoas podem considerar valioso contar com boa saúde, ter uma vida longa, assim como realizar atividades como o trabalho, participar na comunidade, etc. 
Esta visão é crítica de outras abordagens que consideram o aumento de renda como objetivo único na promoção do desenvolvimento 5 . Sobre isto, Sen (2000) argumenta que não existe um elo imediato entre o crescimento econômico e o desenvolvimento humano, pois esses nexos dependem de aspectos como a qualidade e a distribuição dos benefícios e não só da quantidade. Por outro lado, o autor faz uma distinção entre o que são meios e fins do desenvolvimento, considerando a renda como um dos meios (e não o fim) para atingir o bem-estar das pessoas. Maior nível de renda nem sempre garante a ampliação de habilidades e capacidades humanas. Às vezes, só a possibilidade de respirar ar limpo pode evitar doenças respiratórias e expandir a habilidade de contar com boa saúde.

Para Sen (2000), a expansão das liberdades representa simultaneamente tanto um fim em si mesmo como um meio para atingir o desenvolvimento. A liberdade como fim, exerce um papel constitutivo através do qual se concede valor intrínseco à vida humana. Logo, a vida das pessoas deve ser o objetivo primordial do desenvolvimento, independente do que elas possam gerar em termos econômicos. Ser livre de doenças ou do analfabetismo é relevante não só pelo que representa como capital humano no crescimento econômico, mas também pela vida, dignidade, felicidade e autoestima das pessoas.

Ao mesmo tempo, as liberdades representam os meios que as pessoas dispóem para ampliar ainda mais suas liberdades e alcançar seu bem-estar. Elas desempenham o papel instrumental, que concerne a direitos, intitulamentos e oportunidades que promovem a expansão do desenvolvimento humano. Nesse sentido, Sen (2000: 55) aponta cinco formas de liberdade como instrumentos que atuam de forma interligada para ampliar as potencialidades dos indivíduos: i) liberdade política, para votar e eleger, opinar e reclamar; ii) facilidades econômicas para ter acesso a recursos, trocar e consumir; iii) oportunidades sociais através da educação, boa saúde e, assim, interagir com os outros membros da sociedade; iv) garantia de transparência para poder confiar e oferecer confiança; v) segurança protetora para reduzir a vulnerabilidade e riscos frente a guerras, epidemias e incerteza de eventos externos. Adicionalmente, pode-se sugerir um sexto instrumento de expansão do desenvolvimento humano, referente aos recursos e sistemas do meio ambiente, um meio que não é explicitamente mencionado por Sen, mas que é táo importante quanto os outros na promoção de elementos básicos das pessoas, por tratar-se de questóes como a garantia da água que se bebe ou do ar que se respira.

\footnotetext{
${ }^{5}$ Basicamente, a perspectiva das capacitaçôes do Sen, surge como uma crítica às teorias de filosofia política, tais como o Utilitarismo, a teoria Rawlsiana dos bens primários, necessidades básicas, visóes de liberdades formais e libertarismo e perspectivas de renda (Comim et al., 2007).
} 
Sen (2000: 54) realça a qualidade de eficácia da liberdade como meio, pois "diferentes tipos de liberdades apresentam inter-relaçáo entre si, e um tipo de liberdade pode contribuir imensamente para promover liberdades de outros tipos". Por exemplo, maior acesso a serviços de saúde reduz a vulnerabilidade de sofrer epidemias e aumenta a segurança protetora. Ao mesmo tempo, melhores condiçóes de saúde dos indivíduos aumentam as oportunidades sociais de interagir, assim como a possibilidade de trabalhar e acessar a maiores facilidades econômicas. Sen (2000: 71) menciona que "o processo de desenvolvimento é crucialmente influenciado por essas inter-relaçóes". No entanto, esses instrumentos podem ser diminuídos pela ausência de liberdade democrática, pela restrição de direitos, pela desigualdade no acesso ao sistema de saúde e educação, desigualdade na distribuição de alimentos e riquezas, degradação do meio ambiente, limitação no acesso à água e saneamento básico, entre outros aspectos.

Segundo, Comim et al. (2007), a visão de desenvolvimento humano proposta por Sen é importante dada a eficácia das capacitaçóes como base normativa do desenvolvimento e, também, dada a amplitude do espaço informacional ${ }^{6}$ na avaliação do bem-estar, já que integra vários elementos de medida das liberdades concretas que gozam os indivíduos e não se restringe a unidades de julgamento, como a renda ou a utilidade de bens e recursos que possam usufruir os indivíduos, ou necessidades básicas que possam satisfazer. Nessa linha, Sen (2001: 82) menciona que "a perspectiva da capacitação fornece um reconhecimento mais complexo da variedade de maneiras sob as quais as vidas podem ser enriquecidas ou empobrecidas".

De acordo com Sen (2001), o espaço informacional para a avaliação do bem-estar deve compreender um conjunto de funcionamentos ou elementos constitutivos do ser das pessoas, que representam estados e açóes dos indivíduos (beings and doings), como estar adequadamente nutrido, estar livre de doenças, livre de mortalidade prematura, livre para participar e trabalhar, entre outros.

Além do conceito de funcionamentos, Sen $(1985,2000,2001)$ define os conceitos de capacitaçôes e conjunto capacitário. As capacitaçôes refletem a liberdade real para realizar diferentes combinaçóes e alternativas de funcionamentos que são factíveis de alcançar. O conjunto capacitário, por outro lado, representa o grau de liberdade para escolher a combinaçáo de funcionamentos que é valiosa entre varias opçôes. Segundo, Sen (2000: 96), é diferente escolher entre varias opções a ter que aceitar uma única opção disponível, assim "Jejuar não é a mesma coisa que ser forçado a

${ }^{6}$ Espaço informacional refere-se a uma base de juízos de avaliaçấo sobre o bem-estar humano (Sen, 2000) 
passar fome. Ter a opção de comer faz com que jejuar seja o que é: escolher não comer quando se poderia ter comido". É importante destacar que se uma pessoa não conta com alternativas de escolha, seu bem-estar está sendo limitado, ainda que a realização de funcionamentos seja considerada como boa.

A partir da perspectiva seniana, o funcionamento atingido por uma pessoa não é o único relevante para refletir o bem-estar, mas também a capacidade de escolher e discriminar entre possíveis estilos de vida que a pessoa valoriza. Essa ênfase na liberdade de escolha reflete o aspecto da agência, o qual se refere à autonomia da pessoa para buscar seus próprios objetivos e valores (Sen, 2001).

A importância de um espaço amplo de avaliação do bem-estar está ligada à possibilidade de usar os funcionamentos e as capacitaçóes para realizar comparaçôes interpessoais e, por conseguinte, para definir critérios de desigualdades de bem-estar entre os indivíduos. A AC considera a heterogeneidade dos seres humanos e a diversidade de ambientes e de múltiplas condições que tornam diferentes os indivíduos em relação ao seu potencial de conversão dos recursos em diferentes funcionamentos. Por exemplo, se duas pessoas dispóem da mesma quantidade de alimentos, isso não significa que elas tenham a mesma capacidade de estar adequadamente nutridas, pois isto varia de acordo com o metabolismo de cada pessoa, da idade, do gênero e até das condiçóes climáticas (Sen, 2000). Ou seja, a posse da mesma quantidade de bens e de recursos náo garante que todos os indivíduos alcancem idêntico nível de bem-estar, ou ainda, a posse dos bens não reflete a real liberdade da pessoa para escolher um estilo de vida ou outro.

Segundo, Sen (2001), as comparações de bem-estar entre indivíduos não devem ser reduzidas a um espaço em particular, como a renda ou os bens primários. As comparaçóes de bem-estar devem ser feitas em um cenário mais abrangente, considerando a pluralidade de espaços que, em primeiro lugar, refletem as diferenças de qualidades pessoais como habilidades, talentos, idade, gênero, deficiências entre outras, e, em segundo lugar, mostram a diversidade de circunstâncias externas que afetam os indivíduos, como as condiçôes econômicas, políticas, sociais e, inclusive, a dotação e o estado dos recursos naturais e as condições climáticas. Essa diversidade é o que determina o que as pessoas podem ser e fazer, e, portanto, faz com que as pessoas tenham diferentes oportunidades e capacitaçóes para alcançar seu bem-estar.

Considerar o bem-estar humano desde uma perspectiva mais ampla permite levantar questôes em diversas direções, por exemplo, em relação a como a mudança climática pode privar as capacitaçóes dos homens e impor limitaçôes ao bem-estar humano. Autores como Holland (2008) 
e Page (2007) baseados na abordagem das capacitaçóes tem estudado essa problemática em particular direcionando seus argumentos a uma teoria de justiça climática. Por um lado, Holland (2008) propóe a sustentabilidade ambiental como uma capacitação independente ou uma metacapability. Essa definição é no sentido em que a estabilidade ecológica é necessária para exercer todo um conjunto de funcionamentos e capacitaçóes das geraçóes presentes e futuras, incluindo também a oportunidade individual de ter controle sobre seu próprio meio ambiente. Por outro lado, Page (2007) argumenta que a possibilidade de contar com um meio ambiente sustentável constitui um componente vital para uma vida digna e não simplesmente um facilitador de funcionamentos. $\mathrm{O}$ autor realça a importância de exercer capacitaçóes e de experimentar uma vida sem impactos ambientais tais como os ocasionados pela mudança climática.

Em geral, uma abordagem mais ampla do desenvolvimento humano, como a fundamentada por Amartya Sen, reconhece conjuntamente a pluralidade de espaços de avaliaçáo do bem-estar, dentro dos quais, além da renda ou dos bens primários, encontra-se o espaço de avaliaçáo que define a relaçáo entre o bem-estar e os serviços do meio ambiente. $\mathrm{Na}$ análise do bem-estar humano é possível incorporar as diversas formas em que as pessoas dependem dos recursos naturais para viver e as oportunidades que eles oferecem para expandir as capacitaçóes dos indivíduos. A integridade do meio ambiente pode oferecer à pessoa a oportunidade de estar bem nutrido, de desfrutar de boa saúde, de evitar epidemias como a malária e a dengue, de sentir-se seguro, bem como permite a diversificação dos meios de subsistência e a continuaçáo de tradiçóes e culturas. Além do que o meio ambiente possa oferecer, ele representa o suporte para a vida, o fim em si mesmo. Por tal motivo, e tendo em conta que o sistema climático faz parte do ambiente natural, o debate sobre o bemestar humano não pode ignorar questóes sobre a mudança climática.

\subsection{Estrutura de análise para a classificaçáo de impactos da mudança climática sobre o desenvolvimento humano}

Para sistematizar os elos entre a mudança climática e o desenvolvimento humano, utilizam-se como base os fundamentos da Abordagem das Capacitaçóes de Amartya Sen descrita anteriormente, assim como a estrutura conceitual do Millennium Ecosystem Assessment (MA) (2003) no que concernem às conexôes do bem-estar humano com os serviços dos ecossistemas $^{7}$ (provisão, regulação, suporte e cultura). A figura I apresenta parte da estrutura que se seguirá como forma de procura dos nexos.

${ }^{7}$ A Convention on Biological Diversity (CBD) define ecossistemas como: "um complexo dinâmico de comunidades de plantas, animais e microorganismos e do meio ambiente náo-vivo intera- 


\section{Figura I \\ Relaçóes diretas e indiretas da mudança climática e o desenvolvimento humano}

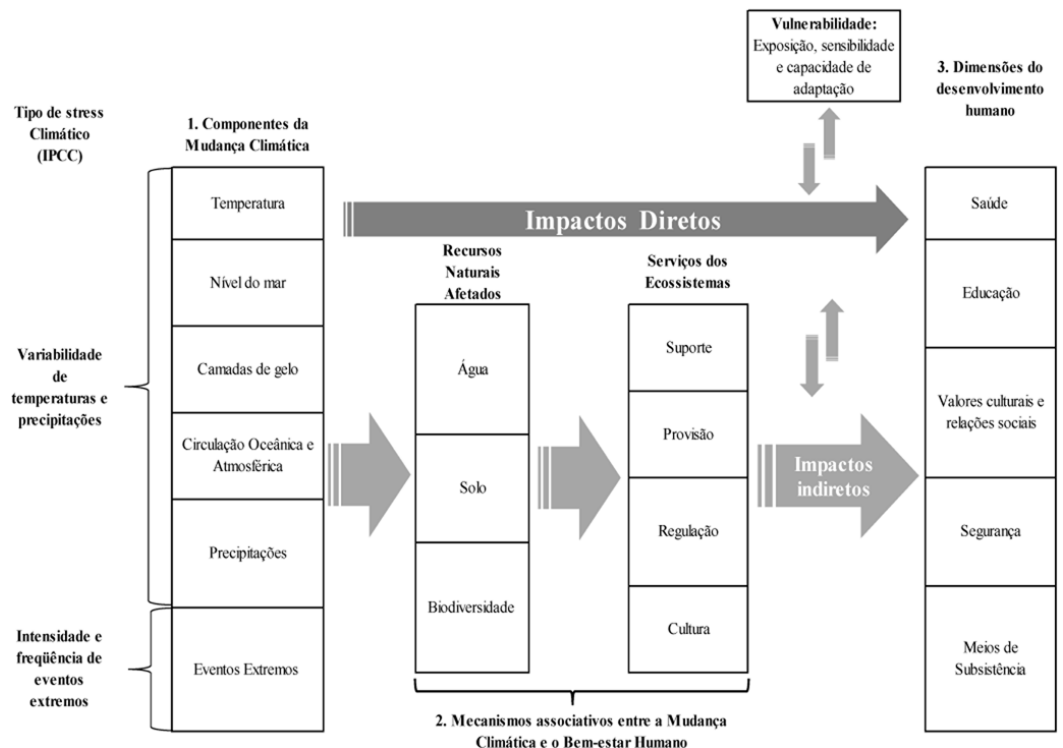

Nota: as relaçóes estáo influenciadas pela interação com aspectos de vulnerabilidade, como a localizaçáo geográfica, o grau de dependência nos recursos naturais e serviços dos ecossistemas e a capacidade de ajustamento a choques climáticos.

Fonte: Elaborado pelos autores.

Conforme a figura I, num primeiro momento, adota-se a classificação dos componentes da mudança climática segundo o IPCC (2007b) que são categorizados de acordo com dois tipos de stress ou perturbação climática. Dentro dessas categorias, os riscos da mudança climática estão associados ao aumento da temperatura e do nível do mar, derretimento da criosfera e aumento da freqüência e intensidade de eventos extremos.

Num segundo momento, identifica-se a existência ou náo de mecanismos associativos, ou seja, de elementos chaves através dos quais é possível inferir o tipo de ligaçóes diretas ou indiretas entre os componentes da mudança climática e o bem-estar humano.

A estrutura aqui apresentada propóe como mecanismos associativos os recursos naturais e os serviços dos ecossistemas que são instrumentais ao bem-estar humano. Tendo em conta que a mudança climática pode afetar, inicialmente, os recursos e sistemas naturais, pode-se dizer que, conseqüentemente, ela também pode afetar indiretamente as capacitaçôes

gindo como uma unidade funcional. Os humanos são uma parte integral dos ecossistemas" (MA, 2003: 49). 
humanas. Por exemplo, as pessoas podem ser afetadas na medida em que os aumentos da temperatura afetam o derretimento de glaciers, alterando assim a oferta de água, que é um recurso indispensável para o consumo e sustento da vida humana. Desse modo, os recursos naturais são considerados os meios através dos quais as alteraçóes climáticas influenciam indiretamente o desenvolvimento humano.

A noção de mecanismos associativos argumenta-se com base na estrutura conceitual da Avaliação do Milênio (MA, 2003), que examina as diferentes formas como os ecossistemas podem expandir ou restringir o bem-estar humano. De acordo com a abordagem do MA (2003), os seres humanos se beneficiam dos ecossistemas em serviços como provisão, suporte, regulação e cultura:

- O serviço de provisão permite o abastecimento de alimentos de origem agrícola, animal e da floresta. Permite a provisão de água fresca para o consumo e a irrigação, a provisão de energia em forma de madeira e recursos fósseis, a provisão de plantas medicinais, essências e fibras utilizadas para a construção de vivendas, utensílios e vestuário.

- O serviço de regulação corresponde aos ciclos e processos realizados pelos ecossistemas para manter o adequado funcionamento dos mesmos, isso compreende a purificação da água, o controle da erosão, a regulação do clima para manter o equilíbrio da temperatura, das precipitaçóes e dos fenômenos naturais do clima e o controle de pestes e doenças que reproduzem organismos patogênicos como o mosquito que transmite a dengue e a malária.

- Os serviços culturais dos ecossistemas representam os benefícios não materiais que recebem as pessoas, como fonte de satisfação, recreação e enriquecimento espiritual.

- Por último, o serviço de suporte possibilita a produção dos outros serviços dos ecossistemas. Ele representa o suporte da vida mesma, pois permite a formação do solo, a produção primaria, a produção de oxigênio entre outros (MA, 2003).

Os serviços dos ecossistemas são essenciais para os seres humanos. Portanto, permite-se inferir que as alteraçóes climáticas afetam indiretamente os constituintes do bem-estar humano, na medida em que alteram a capacidade dos ecossistemas em oferecer seus serviços e dos quais as pessoas dependem para viver e ampliar suas múltiplas dimensões de funcionamentos e capacitaçóes.

Desta forma, definem-se as relaçôes indiretas como aquelas que apresentam um elemento que interliga as duas dimensões, mudança climáti- 
ca e bem-estar humano, sendo esse elemento denominado como mecanismo associativo, constituídos por recursos naturais como o solo, a água e a biodiversidade, assim como seus respectivos serviços dos ecossistemas: produção, regulação, suporte e cultura. Como se observa na figura I, um evento climático pode afetar (negativamente ou positivamente) o bemestar humano na medida em que modifica o estado de algum recurso e serviço do qual o ser humano depende para viver. Essas relaçóes indiretas são representadas através das setas descontinuas na figura I.

Por outro lado, a estrutura define as relaçóes diretas como aquelas nas quais não interfere nenhum outro elemento ou mecanismo entre a ocorrência de um evento e seu impacto sobre o status de bem-estar humano, ou seja, o homem encontra-se em contato direto com o stress climático. $\mathrm{Na}$ figura I, estas relaçóes podem ser representadas pela seta continua que se estende desde os componentes climáticos até os componentes do bemestar humano. Nesse caso, verificam-se os impactos sobre os constituintes de saúde e capacidade de viver das pessoas, avaliado por indicadores de morbidade e mortalidade. Por exemplo, mortes ou doenças causadas por excesso de calor ou por eventos como ciclones e furacóes.

Em terceiro momento, classificam-se os componentes do bem-estar e desenvolvimento humano que são relevantes para o estudo da mudança climática. Como foi comentado na seção anterior, no espaço informacional de avaliação do bem-estar coexistem inúmeros funcionamentos e capacitaçóes que podem ter diferente importância para cada pessoa, dependendo de suas características pessoais, as condições ambientais em que vive e, ainda, pelo próprio julgamento da pessoa, em exercício da sua condição de agente. Em consideração a estes aspectos, não é propósito do Amartya Sen estabelecer uma lista básica de funcionamentos e capacitaçóes para representar o que seria um adequado bem-estar. Mas essa circunstância não significa uma desvantagem da abordagem das capacitaçóes. Muito pelo contrario, Sen (2000) realça que o processo de definição de juízos de avaliação do bem-estar é inescapável, no entanto, esse processo deve ser explícito, ao invés de ser uma valoração implícita. Portanto, o exercício de julgamento na definiçáo de um leque de funcionamentos importantes para o bem-estar humano pode ser gerado através de um processo de escolha social.

Com o intuito de definir os funcionamentos a serem utilizados na análise da mudança climática conforme um processo valorativo explícito, assim como sugere Sen, foram considerados os funcionamentos e categorias apontadas por diferentes estudos para a representação do bem-estar de uma pessoa. Não é pretensão discutir a validade das formulaçóes, tão só ressaltar a existência de perspectivas que são concebidas em conformidade à abordagem das capacitaçóes proposta por Sen. Da mesma forma, 
não se pretende discutir quais seriam as capacitaçóes básicas de uma pessoa, mas "chamar a atenção para aspectos importantes do processo de desenvolvimento, cada qual merecedor de nossa atençáo" (Sen, 2000: 49), e reconhecer a mudança em relação ao que se concebe como bem-estar, não baseada em critérios únicos e implícitos, mas em consideração aos diferentes estados das realizaçóes dos seres humanos.

Importantes trabalhos de referência internacional já utilizaram a abordagem das capacitaçóes tais como os Relatórios de Desenvolvimento Humano com os componentes do Índice de Desenvolvimento $\mathrm{Hu}$ mano (IDH) (PNUd, 2007), Objetivos de Desenvolvimento do Milênio (ODM), Millennium Ecosystem Assessment (MA) (2003) e a lista de capacitações proposta por Martha Nussbaum $(2003,2011)^{8}$. Dessa forma, sintetizam-se os componentes que foram comuns para todos os estudos, sendo estes: a saúde, a educação, os valores culturais e sociais, a segurança e os meios de subsistência. É importante destacar que esses elementos não representam uma lista fechada de capacitaçóes, mas só uma evolução de um debate permanente. Assim, é possível categorizá-los dentro da denominação de liberdades como fim e meio do desenvolvimento humano, apontada por Sen.

Tendo em conta que a liberdade como fim do desenvolvimento humano, alude o valor intrínseco da vida das pessoas, nessa categoria abordam-se os constituintes de saúde, educação e valores culturais e sociais. Analisam-se as diferentes formas em que a mudança climática pode limitar a capacidade das pessoas de serem adequadamente nutridas, de serem livres de doenças evitáveis, de serem livres para consumir água fresca e respirar ar puro sem medo de adquirir doenças como a malária ou infecçóes respiratórias, de serem livres para receber calor e se aquecer e de serem livres para utilizar as medicinas naturais oferecidas pelos ecossistemas. Ademais, descrevem-se os efeitos em relação à capacidade de receber educaçáo, de desfrutar de atividades de turismo e recreaçáo e da oportunidade de viver conforme as tradiçóes e culturas herdadas.

Entretanto, a liberdade como meio do desenvolvimento humano dentro do contexto da mudança climática, inclui as categorias de segurança e meios de subsistência. Nessas categorias descreve-se como a mudança climática coloca em risco a segurança das pessoas através da maior freqüência e intensidade de eventos extremos, aumento do nível do mar e a partir do maior risco de fome e escassez de água induzido pelos choques

${ }^{8}$ Martha Nussbaum (2003: 41-42; 2011:33-34) propóe uma lista de capacitaçóes fundamentais do ser humano em consonância com as concebidas por Sen no objetivo de comparabilidade da qualidade de vida. Entretanto, estas diferem por serem formuladas com a intenção de promulgar uma base de princípios políticos e de direitos universais. A lista inclui as seguintes capacitaçôes: vida, saúde física, integridade física, uso dos sentidos, imaginação, emoçôes, raciocínio prático, afiliação, outras espécies, lazer e controle sobre o próprio ambiente. 
climáticos. Igualmente, descrevem-se os efeitos em relação aos meios de sustento de origem agrícola, de atividades pesqueiras e da floresta e sobre os rendimentos econômicos das diferentes atividades.

Por último, na estrutura de impactos diretos e indiretos, considera-se a interação com fatores de vulnerabilidade, representados pela direção das setas na figura I. A vulnerabilidade refere-se à incapacidade de lidar com os riscos climáticos, comprometendo o bem-estar humano em longo prazo (PNUD, 2007). O Relatório Stern (2007) classifica a vulnerabilidade em termos de exposição, sensibilidade e capacidade de adaptação. A exposição trata da localização geográfica. A sensibilidade define-se de acordo com o grau de dependência na agricultura e nos serviços dos ecossistemas. A capacidade de ajustamento relaciona-se com aspectos de pobreza, status de saúde, educação, acesso à água e ao saneamento básico, acesso à informação e ao seguro de proteção social. Esses fatores de vulnerabilidade são relevantes na análise de impactos, já que permitem estabelecer diferenças de efeitos entre países e regiôes desenvolvidas e em desenvolvimento. Também permitem elucidar por que algumas pessoas podem experimentar impactos mais ou menos intensos sobre suas capacitaçóes humanas.

\section{Mecanismos associativos e impactos potenciais da mudança climática sobre os recursos de água, solo e biodiversidade}

De acordo com o Relatório Planeta Vivo (World Wide Fund for Nature, 2006), os resíduos produzidos pelo homem, entre eles os GEE, já estão ultrapassando a capacidade de absorção e de regeneraçáo dos recursos da Terra. O PNud (2007) destaca que para remover naturalmente os GEE sem comprometer os sistemas ecológicos a longo prazo, devem-se manter emissóes próximas de 1 e $5 \mathrm{Gt}^{9} \mathrm{CO}_{2}$ equivalentes $\left(\mathrm{CO}_{2} \mathrm{e}\right) .{ }^{10}$ No entanto, atualmente as emissóes encontram-se em torno de $48 \mathrm{Gt} \mathrm{CO}_{2} \mathrm{e}$, o que significa que o homem está sobrecarregando o planeta de 10 a 50 vezes além da sua capacidade.

Em todos os cenários de estabilizaçáo de GEE do IPCC (2007b), o associado aumento de temperatura deve ultrapassar $2^{\circ} \mathrm{C}$, que se refere ao limite acima do qual se pode experimentar alteraçóes climáticas perigosas. Inclusive, para uma estabilização de $550 \mathrm{ppm}^{11}$ de $\mathrm{CO}_{2} \mathrm{e}$,

${ }^{9}$ Uma gigatonelada (Gt) é igual a um bilhão de toneladas.

${ }^{10} \mathrm{O} \mathrm{CO}_{2}$ equivalente $\left(\mathrm{CO}_{2} \mathrm{e}\right)$ representa o potencial de efeito de aquecimento global ou "forçamento radioativo" total dos GEE medido em termos de equivalência de Dióxido de Carbono $\left(\mathrm{CO}_{2}\right)$. Compreende gases como: Dióxido de Carbono $\left(\mathrm{CO}_{2}\right)$, Metano $\left(\mathrm{CH}_{4}\right)$, Óxido Nitroso $\left(\mathrm{N}_{2} \mathrm{O}\right)^{2}$ e Halocarbonos. Incluem-se todas as fontes (IPCC, 2007b).

11 “ppm (partículas por milhăo) ou ppb (partículas por bilhão, 1 bilhão $=1,000$ milhōes) é a proporção do número de moléculas de gases efeito estufa do total de moléculas de ar seco. Por 
abaixo do nível mínimo considerado nas projeçôes, há $80 \%$ de probabilidade de exceder $2^{\circ} \mathrm{C}$. Com a estabilização em $650 \mathrm{ppm}$ de $\mathrm{CO}_{2} \mathrm{e}$, a probabilidade encontra-se entre $65 \%$ e $90 \%$ de sobrepassar $3{ }^{\circ} \mathrm{C}$ (PNUD, 2007). Tendo em vista os prováveis aumentos da temperatura relacionados com a maior concentraçao de GEE, existe a possibilidade de exercer uma pressão adicional para a mudança de recursos naturais como a água, o solo e a biodiversidade. No quadro 1, apresenta-se uma sínteses das principais evidências.

Em relação às fontes hídricas, estas devem ser afetadas em duas vias: pela redução da provisão em termos de quantidade e qualidade, e, a partir da maior demanda devido ao aumento da temperatura, especialmente para cobrir os ciclos ambientais da vegetação e da agricultura.

Entre os principais desafios para os próximos anos inclui-se o risco de não contar com suficiente água para a irrigação (Fischer et al., 2007). Globalmente, $70 \%$ da água fresca utiliza-se no setor da agricultura, sendo esse percentual muito maior em regióes como África, Ásia e América Latina ( $86 \%, 81 \%$ e $71 \%$ respectivamente no ano 2001$)$, as quais coincidem em concentrar elevados índices de pobreza rural (Food and Agriculture Organization of the United Nations - FAO, 2006).

A mudança climática deve potencializar dificuldades de escassez de água no futuro. Assim, para o ano 2080, o índice que avalia o nível de escassez de água ${ }^{12}$ em relação à demanda para a agricultura pode aumentar de 14\% (sem mudanças climáticas) para 17\% (com mudanças climáticas). Em países em desenvolvimento essa escassez pode elevar-se de $19 \%$ a $22 \%$. Comparando as estimativas nos cenários sem e com mudança climática a situaçâo é mais grave para África do Norte e Oriente Médio devido a que seu índice de escassez de água pode aumentar de $61 \%$ a $88 \%$. De igual forma, a mudança climática pode levar a uma severa escassez de água no Subcontinente Indiano e no Norte da China (Fischer et al., 2007).

De forma geral, o problema da mudança climática representa um fator adicional para a limitação do recurso hídrico, interagindo com aspectos de gerenciamento, disponibilidade de estruturas físicas de tratamento, desigualdades no acesso e na distribuição. Prevê-se que os maiores impactos sejam em países em desenvolvimento, devido a uma maior utilização de água para a irrigação, maior densidade populacional, e, também, porque estes países contam com um cenário de maiores disparidades no acesso ao recurso.

exemplo: 300 ppm significa 300 moléculas de gases efeito estufa por milhăo de moléculas de ar seco" (IPCC, 2007b: 2).

${ }^{12}$ Ocorre escassez de água quando as retiradas excedem $20 \%$ dos recursos de água renováveis disponíveis no país ou região. Severa escassez de água é quando se excede $40 \%$ (Fischer et al., 2007). 


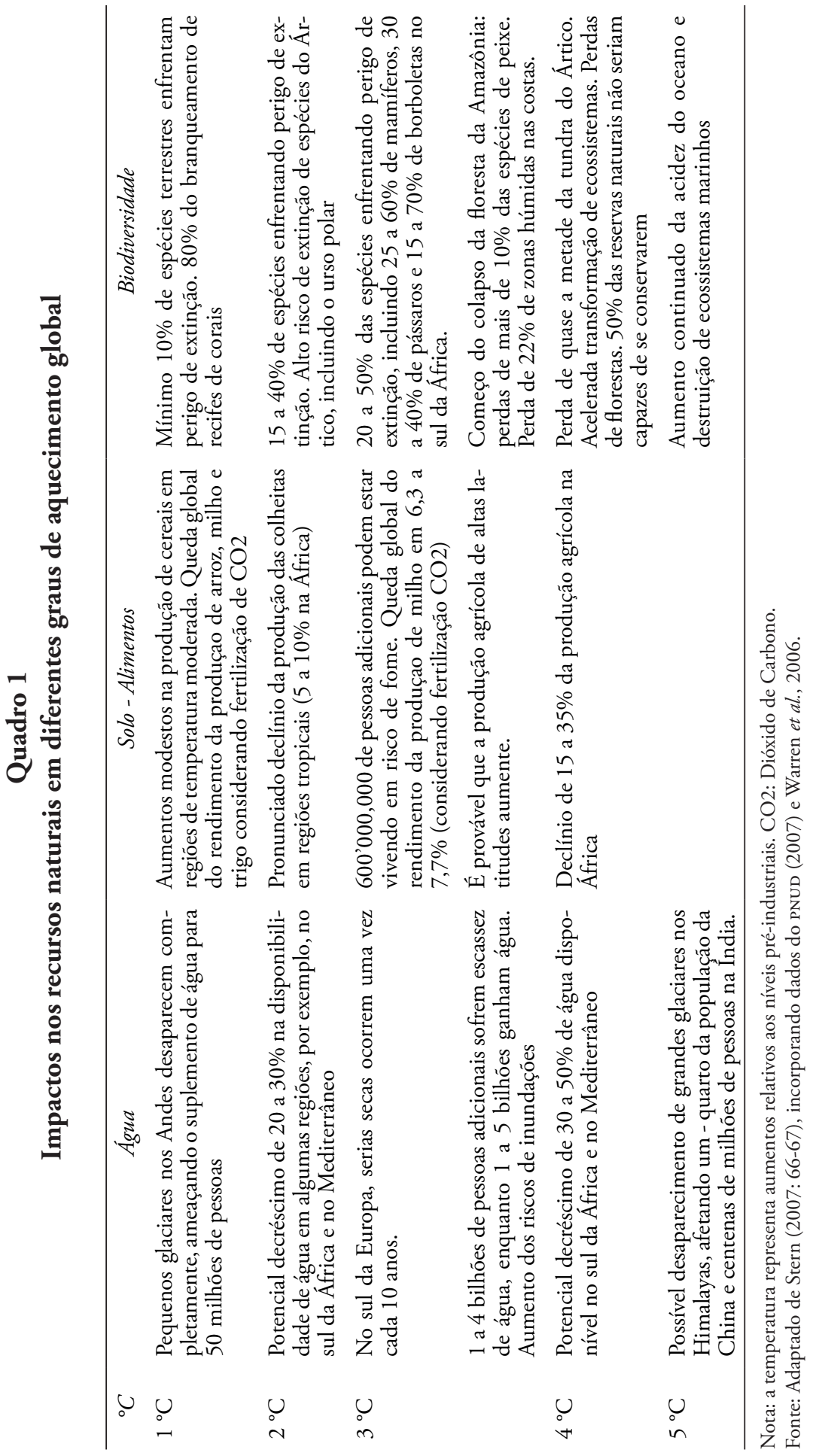


Por outro lado, a mudança climática deve afetar as propriedades do solo e deve mudar os serviços dos ecossistemas oferecidos por esse recurso. Os impactos devem ser maiores para a agricultura, no que diz respeito à quantidade de terra disponível e com potencial de cultivo, assim como em termos de rendimento produtivo. As mudanças da terra e da produção de culturas representam o mecanismo associativo através do qual a mudança climática deve afetar indiretamente o bem-estar humano, em caminhos como mudanças na disponibilidade de alimentos, nos costumes de plantio e em migraçóes para terras mais aptas. Os impactos podem ser positivos ou negativos de acordo com a localização geográfica, o atual status da terra e a dependência da agricultura.

O estudo de Fischer et al. (2002) mostra as projeçóes de impactos sobre o potencial ${ }^{13}$ de área de terra para a produção de trigo, arroz e milho em 2080. Globalmente, tanto o acréscimo da temperatura quanto a combinação com o aumento das precipitaçóes pode trazer ganhos em termos de extensão de terra para o cultivo dessas commodities. Contudo, ao desagregar por regiôes e por nível de desenvolvimento, os impactos são marcadamente diferenciados. Países em desenvolvimento podem perder potencial de terra para a agricultura, diminuindo em um intervalo de $1,3 \%$ a $11,1 \%$. As regióes que podem ser mais afetada são América do Sul (com uma redução entre 4,4\% a 22,7\%), África Central e Sudoeste Asiático. Entretanto, países desenvolvidos podem beneficiar-se com um aumento de $11,1 \%$ a $25,3 \%$ na extensão de suas terras produtivas. No Brasil em particular, os efeitos do aquecimento global sobre a agricultura no período de 2040 a 2069 podem ser equivalente a uma redução do lucro do setor agrícola em uma escala de $0,8 \%$ a $3,7 \%$. Piores resultados esperam-se no período de 2070 a 2099 quando a lucratividade do setor pode diminuir até 26\% (Féres et al., 2011).

Por último, a mudança climática representa uma pressão adicional ${ }^{14}$ que incide na maior perda da biodiversidade ${ }^{15}$ (MA, 2005). O aquecimento global pode acelerar a vulnerabilidade de diferentes tipos de habitat,

\footnotetext{
${ }_{13}$ Potencial de terra para a agricultura corresponde a uma estimação projetada de terra que atualmente não é usada para a agricultura, mas que poderia ser adaptada e convertida à agricultura com um nível de sustentabilidade. Estima-se que 25\% de terra com potencial para a agricultura encontra-se em áreas de floresta e áreas protegidas. Não obstante, a ampliação de terras produtivas será limitada dada a fragilidade ecológica, a incidência de doença e a restrição financeira e de infraestrutura (Fischer et al., 2002).

${ }^{14}$ Os impactos sobre a biodiversidade dependem da interação com outros "estressores" relacionados às atividades humanas, dentre os quais se destacam o desmatamento, a mudanças no uso da terra, o uso intensivo dos recursos, entre outros.

${ }^{15}$ A Convention on Biological Diversity ( $\mathrm{CBD}$ ) define biodiversidade como: "a variabilidade de organismos vivos de qualquer fonte, incluindo, entre outras coisas, os ecossistemas terrestres e marinhos e outros ecossistemas aquáticos e os complexos ecológicos dos que formam parte: compreende a diversidade dentro de cada espécie, entre as espécies e os ecossistemas" (MA, 2003: 51).
} 
como os oceanos, as florestas e habitats de água doce. De acordo com Thomas et al. (2004), a mudança climática nos últimos 30 anos tem sido responsável pelas modificaçóes na distribuição e abundância das espécies. Por outro lado, os modelos climáticos mostram uma tendência a condiçóes mais secas na região da Amazônia em América do Sul ao projetarem maiores níveis de temperatura e reduçóes nas precipitaçôes, o qual constitui um risco para a biodiversidade assim como para o balanço e seqüestro do carbono global (Marengo et al., 2011).

As alteraçóes climáticas afetam indiretamente os constituintes do bemestar humano, pois alteram a capacidade dos ecossistemas em oferecer serviços de provisão, regulação, suporte e cultura, dos quais as pessoas dependem para viver e ampliar seus funcionamentos e capacitaçôes. No quadro 2, classificam-se as principais evidências de impactos potenciais da mudança climática sobre os serviços dos ecossistemas nos recursos de água, solo e biodiversidade.

O stress que a mudança climática pode exercer sobre os recursos naturais deve danificar e diminuir a oferta dos serviços dos ecossistemas. Por exemplo, a mudança climática pode alterar as propriedades de purificação da água, pode modificar os fluxos e transporte de nutrientes, permite a acomodação de espécies invasoras e altera os habitats aquáticos. Tendo em conta esses aspectos, na próxima seção, os impactos sobre os recursos naturais e os serviços dos ecossistemas serão relacionados com os constituintes do bem-estar.

\section{Impactos potenciais da mudança climática no desenvolvimento humano}

\subsection{Impactos na saúde}

Amartya Sen (1985: 17) argumenta que "o bem-estar de uma pessoa é melhor visto como um índice dos funcionamentos da pessoa”. Esses funcionamentos compreendem aspectos elementares como "estar adequadamente nutrido, estar em boa saúde, livre de doenças que podem ser evitadas e da morte prematura”. De igual forma, isso tem a ver com realizaçóes mais complexas como ser feliz, sentir respeito próprio, participar da vida em comunidade, entre outras. Os funcionamentos determinam o que se pode ser e fazer e refletem parte do estado das pessoas.

Desde essa perspectiva, o julgamento de bem-estar está associado a múltiplos estados e açóes dos indivíduos, entre os quais, encontra-se o estado de saúde desfrutado pelas pessoas. A saúde representa uma das condiçóes mais importante da vida e um componente das possibilidades humanas que deve ser valorado (Sen, 2002). Se os indivíduos são bem 


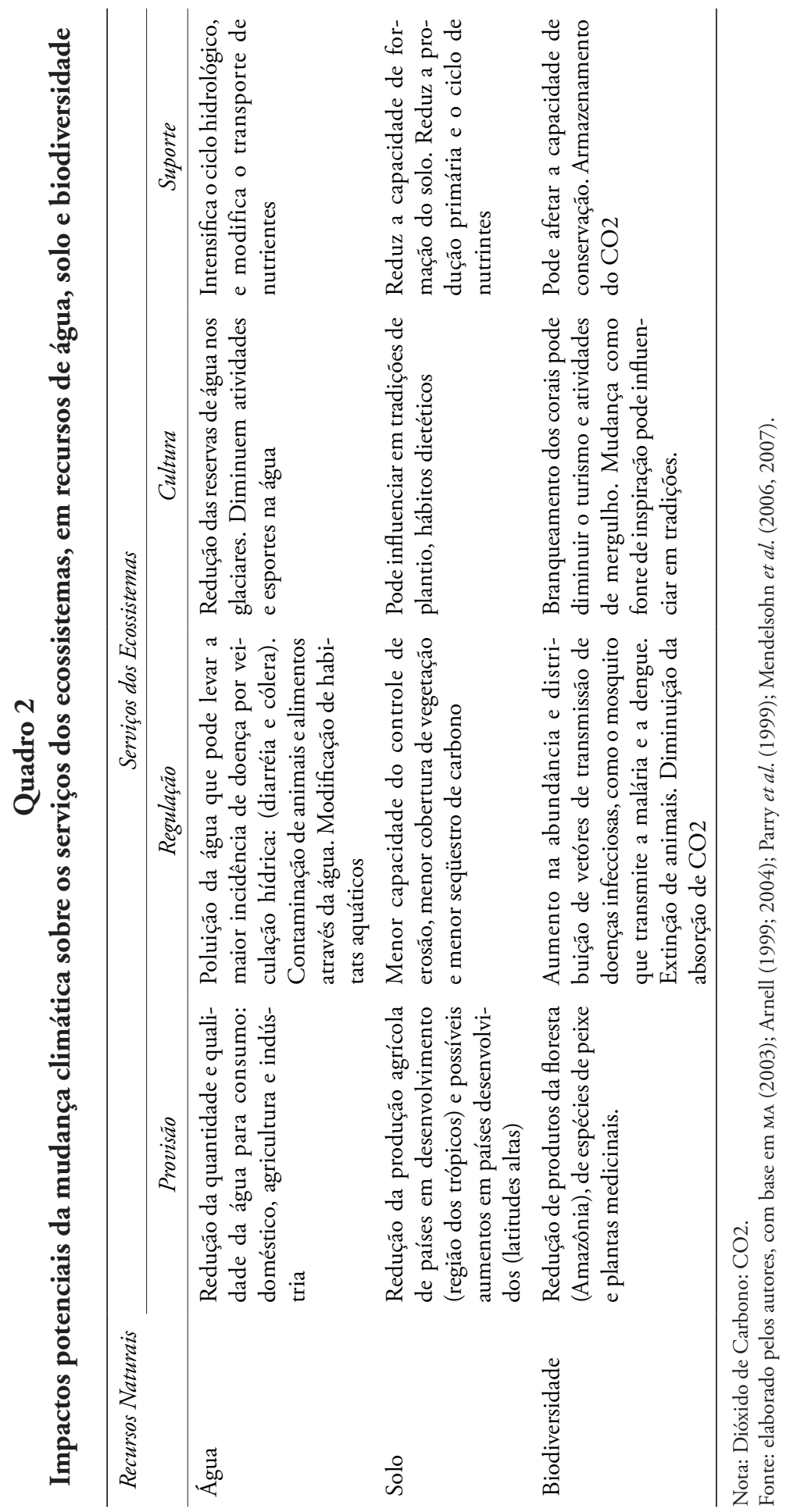




\section{Entra encarte Figura II (frente)}


Entra encarte Figura II (vuelta /

blanca) 
nutridos ou se são livres da malária, ou livres da morte prematura, deve ser intrinsecamente importante como parte do bem-estar da pessoa.

Algumas pessoas não têm oportunidades de atingir adequada saúde devido às múltiplas carências às quais são submetidas e a condiçôes que talvez não foram escolhidas, como por exemplo, o fato de padecer de uma doença associada à contaminação da água ou do ar. No contexto da mudança climática, dada a interdependência ecológica, a possibilidade de escolher uma vida saudável pode estar sendo limitada por emissóes de GEE de outras pessoas. Até o ano 2000, a mudança climática foi responsável por mais de 150,000 mortes associadas à malária, diarréia, subnutrição e mortes por enchentes (McMichael et al., 2003).

$\mathrm{Na}$ análise dos impactos, as interaçóes entre a mudança climática e a saúde podem ser estabelecidas de forma direta e indireta conforme é apresentado na figura II e na qual são sistematizados os processos de impactos potenciais. Nessa figura é possível notar que os impactos na saúde são definidos, além das condiçôes dos recursos naturais, pela interação com fatores de vulnerabilidade pré-existentes. Assim, por exemplo, o grau de impacto por doenças associadas com a água vai depender das condiçóes de acesso, de tratamento da água, dos preços, bem como de questóes institucionais no que diz respeito ao cuidado e sistema público de saúde. Os fatores de vulnerabilidade, definidos por condiçóes sociais, econômicas e institucionais, determinam, no final, a gravidade de impactos da mudança climática.

Pode-se observar na figura II que os efeitos diretos ocorrem devido à sensibilidade e exposição do homem a ondas de calor e eventos extremos. Em Agosto de 2003, a França experimentou uma intensa onda de calor que provocou 14,800 mortes, das quais $60 \%$ eram pessoas acima de 75 anos. Nessa época, para toda Europa foram registradas 35,000 mortes, as quais foram relacionadas com a mudança climática (Hemon e Jougla, 2004).

Por outro lado, as evidências apontam que os impactos indiretos dos choques do clima através dos efeitos sobre os recursos hídricos, o solo e a biodiversidade devem ser mais intensos do que os impactos diretos. No que se refere à escassez, contaminação e em geral a crise mundial da água acelerada pela mudança climática, pode-se comprometer o desenvolvimento humano sob dois aspectos: i) falta de água para a vida e ii) falta de água como meio de subsistência (PNUd, 2006). Sobre o primeiro aspecto, o PNUD (2006) aponta o risco sobre a saúde humana, tendo em conta que 1,8 milhóes de mortes infantis anuais são associadas à água.

Em alguns países, os casos de doenças de veiculação hídrica aumentaram depois da ocorrência de eventos extremos do clima. Após a enchente de 1998 em Bangladesh, as crianças e as pessoas acima de 50 anos 
foram mais susceptíveis à diarréia associada com a mudança na qualidade da água (Kunii et al., 2002). Para o ano de 2030, o risco de diarréia pode ser $10 \%$ maior do que em condiçóes sem mudança climática (McMichael et al., 2003).

Em relação aos impactos potenciais através do mecanismo solo, considera-se a associação com a maior incidência de desnutrição. Varias são as causas da desnutrição, mas as alterações climáticas podem ser um fator adicional para ampliação da vulnerabilidade frente ao risco de fome. A mudança climática sobrepóe-se a uma realidade de deficiência nutricional, sendo a subnutrição em países em desenvolvimento responsável por 3'500,000 de mortes cada ano (Black et al., 2008). Atualmente há $854^{\prime} 000,000$ de pessoas subnutridas e estima-se que para 2080 o número ascenda para 600’000,000 de pessoas adicionais com subnutrição, devido à redução da produção agrícola projetada com as alteraçóes do clima (PNUD, 2007). A desnutrição infantil deve aumentar mesmo sem a mudança climática, porém, com as alteraçóes climáticas das próximas décadas, o risco de fome nas crianças deve aumentar muito mais (Confalonieri et al., 2007).

O estado nutricional é uma questão importante quando se pensa no desenvolvimento humano. Se as pessoas não desfrutam de uma adequada nutrição, dificilmente podem desenvolver outros funcionamentos e capacitaçóes. As pessoas desnutridas podem sofrer de outras doenças, e, além disso, a desnutrição é uma deficiência que pode ser transferida da mãe para o filho. Uma pessoa desnutrida é privada de realizar labores produtivos, pode se tornar menos capacitada para certas atividades. Igualmente, uma pessoa que passa fome pode ser muito infeliz. A açáo de comer pode significar um momento prazeroso e de muito valor para uma pessoa, e a incapacidade de viver esse momento e funcionamento priva a pessoa de uma vida feliz.

Por último, em relaçáo aos impactos através da biodiversidade, a combinação de várias perturbaçóes, entre elas a mudança climática, pode modificar a função de regulação epidemiológica exercida pelos ecossistemas e pode alterar os habitats de vetores biológicos de transmissão, tornando-os mais ou menos sustentáveis para a procriação de organismos patogênicos. Doenças como a malária e a dengue constituem a maior ameaça em um cenário com mudança climática, devido à forte associação com padróes climáticos (McMichael et al., 2003). Para 2080, projeta-se uma populaçáo adicional em risco de malaria de 220'000,000 a $400 ’ 000,000$ de pessoas. Entre as regióes com maior risco encontram-se África subsaariana (38’000,000 a 67’000,000 de pessoas para 2080) e Ásia Ocidental e Oriental (incluindo China) (Van Lieshout et al., 2004). 
Como foi comentado, com as condiçôes atuais do clima, já existe uma fragilidade do estado de saúde associado com a má qualidade da água, limitado acesso a alimentos, limitado tratamento e prevenção de doenças infecciosas. E, nesse quadro de vulnerabilidade, as alterações do clima aparecem para reforçar o padrão de privaçóes experimentado pelas pessoas. As mudanças climáticas impóem restrições ao desenvolvimento humano justamente entre aquelas pessoas já expostas a grandes privaçóes.

\subsection{Impactos potenciais em valores culturais e relaçóes sociais}

A mudança climática pode alterar tradiçóes, atividades de recreação, lazer e turismo. Igualmente, há probabilidade de que os choques do clima influenciem relaçóes sociais de comunidades e países e motive conflitos sobre os recursos naturais (Barnett e Adger, 2007).

A mudança climática pode afetar diferentes formas de recreação e lazer das pessoas através dos impactos em zonas de montanhas, lagoas, ilhas e praias. Impactos negativos incluem danos de infraestrutura, danos em sistemas ecológicos terrestres e marinhos e recursos naturais. A seguir, apresentam-se dois exemplos da relação entre mudança climática e turismo:

i) Impactos sobre costas e praias: As costas constituem a maior ameaça de impactos da mudança climática sobre o turismo (Todd, 2003). O aumento do nível do mar deve causar erosão de praias, inundaçóes de planícies, destruição de ecossistemas costeiros, salinização de aqüíferos e submersão de ilhas (Dasgupta et al., 2007).

ii) Impactos sobre Montanhas: devido ao aumento da temperatura, a estação do inverno deve ser mais curta e as camadas de neve devem diminuir, o que deve prejudicar as atividades de esqui e esportes dessa estaçáo (Elsasser e Bürki, 2002). Para cada aumento de $1^{\circ} \mathrm{C}$ na temperatura, o limite das neves perpétuas deve reduzir em 150 metros. Na regiáo dos Alpes, na Suíça, um aumento de $2^{\circ} \mathrm{C}$ na temperatura sem mudança nas precipitaçóes reduziria a estação de neve em 50 dias por ano (Beniston et al., 2003).

Há evidências sobre a relação entre mudança climática e seus impactos sobre o turismo, recreaçáo e lazer, porém, o que significa isso em termos do bem-estar humano? Por um lado, as pessoas valoram lugares e atividades simplesmente pelo fato de existirem, também como uma forma de enriquecimento espiritual, desenvolvimento cognitivo, reflexão, inspiração e experiências de conhecimento cultural (MA, 2003). Dessa forma, o bemestar do individuo deve depender da capacidade e oportunidade de desfrutar e apreciar da existência de lugares e atividades que são valiosos para 
ele. Com a mudança climática muitas das paisagens apreciadas pelas pessoas podem-se tornar áridas e sem diversidade. Por outro lado, lugares e atividades de recreação e turismo fazem parte dos meios de subsistência de muitas pessoas em todo o mundo e cerca de 10\% do pIB global é gasto em recreação e turismo (Berrittella et al., 2006). No entanto, a mudança de temperatura, precipitaçóes e aumento do nível do mar devem influenciar esses meios de vida através dos impactos sobre locais como praias, montanhas e recursos naturais. Em conseqüência, o estado de bem-estar das pessoas e o futuro desenvolvimento humano deve ser restringido na medida em que seus meios de subsistência derivados do turismo são alterados.

No que se refere aos impactos sobre as relaçóes sociais, Barnett e Adger (2007) apontam dois fatores através dos quais a mudança climática associa-se a conflitos e violência. $\mathrm{O}$ primeiro refere-se aos efeitos sobre os meios de subsistência, já que tanto a atual limitação quanto a percepção futura de incerteza na provisão destes meios pode aumentar o risco de disputa pelos recursos naturais que atravessam fronteiras de comunidades, seja dentro de um país ou entre os países. O segundo fator consiste na possível fragilidade das funçóes e capacidade de resposta do Estado frente a choques climáticos. A probabilidade de ocorrência de conflitos vai depender da capacidade das instituiçóes (entre elas o Estado) em gerenciar os impactos adversos da mudança climática, resolvendo questóes, tais como: maior demanda de assistência médica, aumento de morbidade e mortalidade, migração (incluindo rural-urbano), disputas pelos recursos e meios de vida, entre outros. De forma geral, os autores argumentam que a mudança climática não causa a violência, mas afeta os parâmetros que podem gerar os conflitos.

\subsection{Impactos sobre a educaçáo}

Os impactos relacionados à educação são pouco comentados na literatura, talvez pela falta de geração de informaçãa. No entanto, a educação é influenciada pela ausência de serviços de ecosistemas tais como a água, o solo e a alteração da biodiversidade, assim como a partir dos efeitos sobre outros componentes do bem-estar, principalmente a saúde. Muitas crianças de países em desenvolvimento devem caminhar longas distâncias em procura de água até as fontes de abastecimento, impedindo assim, a freqüência às escolas. Segundo o Fundo das Naçôes Unidas para a Infância - UNICEF (2008), no sul da Madhya Pradesh, na Índia, as meninas gastam mais tempo na procura da água (em torno de três horas por dia) do que no aprendizado. Como conseqüência, elas apresentam menor desempenho acadêmico do que os meninos. As crianças também podem 
ser restringidas de irem à escola por apresentarem doenças de veiculação hídrica, como a diarréia, a qual mata diariamente em torno de 4,800 crianças (PNUD, 2006).

Outra questáo que se levanta é a desigualdade de gênero que pode ser ampliada em razão das alteraçôes do clima. Aquelas mulheres mais expostas a eventos climáticos mais extremos podem ter as suas capacitaçóes mais comprometidas. As mulheres da Índia, por exemplo, que nasceram em períodos de secas ou enchentes, têm 19\% de probabilidade de não terem ensino fundamental, comparado com aquelas mulheres da mesma idade e que não nasceram em períodos de desastres climáticos (PNUD, 2007).

Por outro lado, doenças como a malária representam uma ameaça latente para o futuro desenvolvimento cognitivo e capacidade de aprendizado. A malária é responsável pela morte de mais de um milhão de pessoas cada ano, das quais, $75 \%$ são crianças africanas menores de cinco anos (Organização Mundial da Saúde - oms e unicef, 2005). As evidências mostram que a mudança climática pode aumentar a incidência de malária, só na áfrica estima-se que haja 56,000 mortes adicionais por cada grau $\left({ }^{\circ} \mathrm{C}\right.$ ) de aumento da temperatura média global (Tol e Dowlatabadi, 2001). Isso significa que sem um processo de ajustamento, existe o risco de aumentar o número de crianças afetadas por essa doença e, conseqüentemente, maior o número de crianças incapacitadas para ir à escola. As crianças que sobrevivem aos casos graves de malária cerebral podem sofrer de paralisias parciais, padecer de convulsóes, problemas de elocução, constantes febres e problemas de aprendizado (oms e UniCEF, 2005).

Em outro sentido, os desastres naturais também podem afetar a educação, destruindo a infraestrutura das escolas, como aconteceu em Honduras durante o furacão Mitch em 1998, que devastou 25\% das escolas desse país (Stern, 2007). Em geral, as pessoas pobres são mais vulneráveis a desastres do clima, porém, as crianças são mais ainda. Em Julho de 2007, Bangladesh experimentou fortes monçôes de chuvas que afetaram 4’200,000 de crianças, das quais 300,000 foram crianças menores de cinco anos. Em todo o Sudoeste Asiático os desastres climáticos destruíram em torno de 3,000 escolas de ensino fundamental. Na África, no mesmo ano de 2007, quase 200 escolas foram destruídas, o que afetou a 45,000 crianças (UNICEF, 2008).

\subsection{Impactos sobre os meios de subsistência}

A mudança climática ameaça os diferentes meios de subsistências que dispóem as pessoas, especialmente das comunidades pobres que vivem no setor rural. Esses meios referem-se ao conjunto de atividades, ativos e 


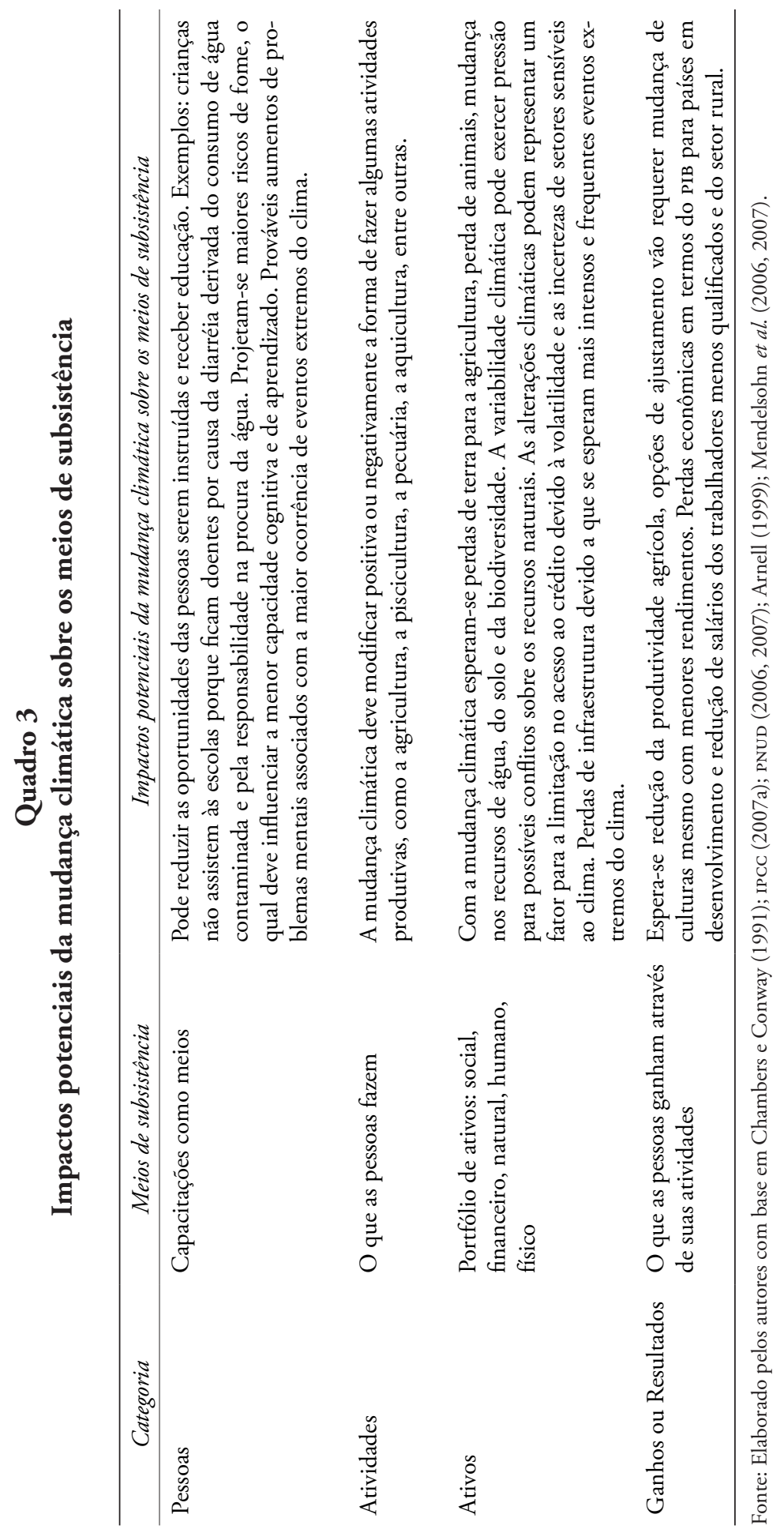


capacitaçóes humanas que utilizam as pessoas para obter a renda e em geral, todo o necessário para o sustento (Chambers e Conway, 1991).

As alteraçóes climáticas aumentam a probabilidade de redução da renda de países em desenvolvimento através das perdas da produção agrícola e outras atividades produtivas (Mendelsohn et al., 2006). Além disso, com as secas e outros desastres climáticos, as pessoas podem ser obrigadas a vender suas terras e recursos e serem forçadas a deslocamentos (Perch et al., 2008).

No nível macro, o estudo de Mendelsohn et al. (2006) estima que a mudança climática pode afetar os mercados de setores econômicos que são sensíveis ao clima, como a agricultura, a água, a energia, a madeira e atividades das costas. As alteraçóes climáticas projetadas para o ano de 2100 devem gerar impactos econômicos tanto positivos como negativos. Os benefícios econômicos podem representar em torno de 0,10\% do Produto Interno Bruto (PIB) global por ano, no entanto, existe também a probabilidade de perdas econômicas de até $0,13 \%$ do PIB global cada ano. Nesse processo, a maior preocupação tem a ver com a distribuição desses impactos, com possíveis prejuízos desproporcionais ficando para países pobres. Por exemplo, o quartil de países mais pobres pode sofrer perdas econômicas equivalentes entre $12 \%$ a $23,8 \%$ do PIB por ano. Em comparaçáo, os impactos negativos para o quartil de países mais ricos podem representar $0,1 \%$ do PIB, e ainda, com a possibilidade de aumentarem seus benefícios econômicos que podem representar $0,9 \%$ do PIB por ano.

Outro estudo de Mendelsohn et al. (2007) sugere que a variabilidade do clima constitui um determinante da renda e da pobreza rural. O referido trabalho estima que no Brasil um aumento de temperatura de $10 \%$ poderia diminuir a renda rural em $5,5 \%$. Em países desenvolvidos como Estados Unidos essa relação seria menor e um aumento da temperatura na mesma proporção, reduziria a renda rural em 0,16\% (Mendelsohn et al., 2007).

O aquecimento global também representa uma ameaça à biodiversidade marinha através do branqueamento e morte dos corais, o qual, por sua vez, afeta a produtividade de zonas pesqueiras. Em 1998, os fenômenos de El Niño causaram a morte de $16 \%$ dos corais do mundo, principalmente os do Caribe. A combinação de várias perturbaçóes, entre elas o aumento da temperatura, pode causar a perda de $60 \%$ dos corais em 2030 (Allison et al., 2005). Ainda, a perda de corais associada à mudança climática, pode levar a uma redução do consumo per capita de peixe em até $0,3 \%$ para 2015, em relação ao consumo de 2000 (Allison et al., 2005).

A pesca é altamente vulnerável à mudança climática e as projeçóes indicam probabilidade de perda de dias adequados para realizar atividades de pesca. As previsóes também apontam para uma modificação das espé- 
cies de peixes e a interrupção de padróes reprodutivos e rotas de migração. Como conseqüência, projetam-se impactos sobre as pessoas em termos de rentabilidade, impactos indiretos pela perda desse meio de sustento, risco de cólera pela intoxicação do peixe e de desnutrição pela falta dessa proteína (Allison et al., 2005). No quadro 3 apresenta-se uma síntese dos impactos potenciais da mudança climática sobre os meios de subsistência.

A mudança climática afeta diretamente os meios de subsistência quando ocorrem enchentes, secas, ciclones, tufóes, entre outros. Esses eventos causam injúrias físicas, destroem infra-estruturas, arrasam plantaçóes e animais e degradam recursos naturais como a água e o solo. Por outro lado, os choques climáticos ameaçam indiretamente os meios de vida, na medida em que os impactos sobre os recursos naturais e seus ecossistemas afetam outros meios de sustento ou impedem a permanência destes ao longo do tempo.

A mudança climática obriga à maioria das pessoas pobres a mudarem de atividades e a trocarem seus meios de subsistência, mesmo que essa mudança implique maiores prejuízos para seu bem-estar. As pessoas pobres de países em desenvolvimento são mais vulneráveis às alteraçóes climáticas, dadas as dificuldades que possuem para ampliar e diversificar seus ativos e meios de vida.

\subsection{Impactos sobre a segurança}

A segurança refere-se à garantia para a pessoa exercer suas capacitaçóes e liberdades sem o temor de perdê-las ao longo do tempo. Isso implica a garantia de não serem prejudicados por desastres naturais e não naturais. Tem a ver com a garantia no acesso de ativos, da confiança de viver em um ambiente controlado e previsível e garantia para desfrutar de sustentabilidade ambiental (MA, 2003).

No âmbito da mudança climática, a segurança humana é determinada pela interação entre riscos e vulnerabilidade a choques do clima. Por um lado, risco se refere à variabilidade, incerteza e probabilidade de experimentar resultados adversos (Hansen et al., 2004). Os riscos compreendem eventos externos de controle limitado como as tempestades, enchentes, extrema temperatura, entre outros. Por outro lado, a vulnerabilidade significa a exposição, fragilidade e a incapacidade de lidar com os riscos, comprometendo o bem-estar humano ao longo do tempo. A vulnerabilidade aumenta quando há maior probabilidade de que ameaças externas produzam impactos mais severos (PNUD, 2007).

A segurança dos indivíduos diminui quando existem ameaças e incertezas climáticas latentes que interagem com incapacidades humanas préexistentes, que obrigam às pessoas a tomarem decisóes que muitas vezes reduzem ainda mais seu bem-estar. Frequantemente, as pessoas não têm 
outra escolha a não ser a de uma vida com medo e incertezas. Por exemplo, frente ao risco de fome, as pessoas decidem diminuir suas dietas de modo a garantir pelo menos uma porção de comida cada dia, ou pior do que isso, submetem-se à incerteza de que um dia comem e outro dia não comem. Igualmente, face ao risco de inundaçóes em zonas costeiras, as pessoas se vêm obrigadas a migrar a outros lugares deixando seus patrimônios e seus ativos de vida. A seguir, apresentam-se três mecanismos a partir dos quais os riscos climáticos diminuem a segurança das pessoas:

\subsubsection{Riscos diretos: Insegurança pelo risco associado com o aumento do nivel do mar e eventos extremos}

O aumento em um metro no nível do mar pode comprometer o bemestar de 56’000,000 de pessoas em países em desenvolvimento. Essa cifra representa a populaçáo com potencial de deslocamento por causa do aumento no nível do mar. Maiores riscos devem ser enfrentados por pessoas que vivem em 21 mega-cidades localizadas em zonas costeiras (de 33 que existem com mais de 8'000,000 de habitantes), as quais, por sua vez, têm aumentado significativamente seu tamanho nas últimas três décadas (exceto Tóquio). As áreas das costas ocupam $20 \%$ da superfície da terra do mundo, e mesmo assim, elas concentram $41 \%$ da população global (IPCC, 2007a).

Outro tipo de perturbação climática que ameaça a segurança das pessoas tem a ver com os efeitos de eventos extremos do clima, como secas, inundaçóes e tempestades de vento. O IPCC (2007b) assegura que há maior probabilidade que eventos extremos sejam mais intensos e freqüentes no século Xxi. Os eventos extremos podem-se converter em desastre quando a sociedade e os ecossistemas não são capazes de enfrentálos efetivamente (IPCC, 2007b).

Países ricos e países pobres apresentam diferentes riscos e vulnerabilidade a desastres climáticos. Uma idéia clara percebe-se ao comparar o número de afetados por desastre entre cada grupo de países. Para os países em desenvolvimento, 1 em cada 19 habitantes foi afetado por desastres climáticos no período de 2000 a 2004, sendo essa relação para países desenvolvidos de $1 \mathrm{em}$ cada 1,500 habitantes, no mesmo período (PNUD, 2007).

Além das diferenças no status de vulnerabilidade a eventos extremos, os países devem ampliar suas desigualdades ao considerar a capacidade de adaptação. Cada país, de acordo com o evento climático ao qual esteja mais sujeito e segundo seu grau de vulnerabilidade, deve precisar de diferentes medidas de ajustamento. Porém, países pobres devem-se adaptar a condições mais restritas. 
Os desastres climáticos, além de afetarem profundamente os indivíduos no momento do evento, mudam o trajeto de vida das pessoas para um caminho muito mais difícil, com pouca probabilidade de retornar a seu estado inicial de bem-estar, pois os efeitos não somente abrangem impactos econômicos ou de infraestrutura, aspectos que talvez sejam recuperados facilmente, mas trata-se de efeitos sobre a saúde e emoçôes das pessoas, os quais devem permanecer para o resto das suas vidas.

A capacidade de fazer frente a esses impactos amplia o hiato do desenvolvimento humano. O PNUD (2007) considera que os eventos extremos representam uma armadilha para a evolução do bem-estar. Países com maior pobreza e menor desenvolvimento humano apresentam também limitada capacidade de gerenciar os riscos climáticos, devido a que estão localizados em regióes de maior exposição e de maior ocorrência de eventos extremos, contam com grande densidade populacional e dependência do setor rural, dependem mais dos serviços dos ecossistemas, contam com recursos naturais fragilizados, e as populaçóes vivem em situaçóes de precariedade, em termos habitacionais, de saúde, etc.

\subsubsection{Risco Indireto: Insegurança pelo risco de escassez de água derivada da mudança climática}

A mudança climática coloca em risco a vida e subsistência das pessoas ao modificar a distribuição e disponibilidade da água. Regiōes devem experimentar ao mesmo tempo aumento e redução de áreas com deficiência hídrica. Para 2025, em um cenário com mudança climática e de elevado crescimento da população, a previsão é de que o número de pessoas que vive com stress de água a nível mundial aumente entre 374’000,000 a 1'600,000,000,000 de pessoas (Arnell, 2004).

Nesse contexto, o que pode acontecer com a segurança do bem-estar humano se a mudança climática acelera e intensifica a escassez da água? O problema não se refere simplesmente à redução da quantidade de água, mas à combinação com outros fatores considerados na limitação do recurso, como o gerenciamento, a disponibilidade de estruturas físicas de tratamento, o acesso e a distribuição. O problema da água, além da escassez induzida pelo aquecimento global, é que induz a um cenário de desigualdade onde as pessoas pobres acabam pagando preços mais elevados pelo uso da água do que pessoas ricas. Por exemplo, em países como Quênia e Filipinas, as pessoas pagam 5 a 10 vezes mais que indivíduos que vivem na Inglaterra (PNUD, 2006).

A vulnerabilidade à mudança climática aumenta quando se soma à deficiência de infra-estrutura no suplemento da água. Quando as pessoas não dispóem de rede de água dentro dos domicílios elas procuram utilizar 
pontos coletivos de abastecimento, como poços, caminhão pipa ou diretamente dos rios. A questão é que esse tipo de abastecimento submete as famílias a condições restritas, induzindo à reutilização da água para conseguir poupá-la e evitar vários deslocamentos, ou, forçando a consumir água suja. $\mathrm{O}$ fato de reciclar a água e o inadequado gerenciamento dentro da casa deve causar a contaminação do recurso, o qual, por sua vez, pode comprometer a saúde da família. Assim, por exemplo, a maior incidência de diarréia após a enchente de 1998 em Bangladesh, foi entre pessoas mais pobres, que armazenavam a água em garrafas e que não realizavam nenhum tipo de tratamento no recurso antes de bebê-la (Kunii et al., 2002).

\subsubsection{Risco indireto: Insegurança pelo risco de fome associado com as perdas de produtividade em paises em desenvolvimento devido à mudança climática}

Com a mudança climática há probabilidade de que as pessoas experimentem insegurança alimentar devido aos maiores riscos de eventos extremos do clima e à combinaçáo com fatores de vulnerabilidade dos domicílios sobre os meios disponíveis para obter alimentos. Nos países em desenvolvimento, o aumento de $3^{\circ} \mathrm{C}$ na temperatura media global deve adicionar em torno de 600 milhóes de pessoas em risco de fome, comparado com as estimativas de referência sem mudança climática para o ano de 2080. Além disso, os estudos não mostram otimismo ao considerar as vantagens do comercio internacional, devido também à subida nos preços dos alimentos e à reduzida capacidade de compra de países pobres (Warren et al., 2006).

Diante dos choques climáticos, as pessoas podem não suprir suas necessidades nutritivas e, ainda, as pessoas podem perder a opção de se alimentar de acordo com suas preferências dietéticas e culturais. Como resultado das opções de ajustamento às alteraçóes climáticas, os camponeses devem-se deslocar a outras terras ou mudar produtos de cultivo por outros mais resistentes, os quais por sua vez, devem mudar os alimentos para o consumo.

\section{Conclusóes}

O objetivo principal deste artigo foi identificar e caracterizar os processos pelos quais a mudança climática afeta os determinantes do desenvolvimento humano, sendo estes os funcionamentos e capacitaçóes do indivíduo, bem como os meios e os intitulamentos que promovem o bem-estar das pessoas. 
O estudo argumentou a existência de relaçóes diretas e indiretas entre perturbaçóes climáticas e componentes humanos como a saúde, a educação, meios de subsistência, segurança, valores culturais e relaçóes sociais. Foi possível estabelecer mecanismos associativos que interligam as duas áreas, sendo estes, os recursos naturais de água, o solo e biodiversidade assim como seus respectivos serviços dos ecossistemas.

Por outro lado, a análise teórica contribuiu ao entendimento de como o bem-estar das pessoas pode ser avaliado considerando aspectos ambientais e climáticos, interpretaçôes que vão além de dimensôes tradicionais como o nível de renda ou de bens disponíveis pelos indivíduos. Isto foi plausível considerando uma visão ampla de desenvolvimento humano, como a fundamentada pela Abordagem das Capacitaçóes, a qual reconhece a pluralidade de dimensóes do ser humano, concernente a funcionamentos de realizaçóes e açóes que são valoradas pelas pessoas, como a saúde, a segurança, a educação e os valores culturais, os quais podem ser influenciados pelas condiçóes ambientais e do sistema climático. A abordagem considerada neste artigo é uma perspectiva normativa e multidimensional, abrangendo as diversas formas em que as pessoas são e podem ser privadas de desfrutar uma vida que valorizam devido às condiçóes climáticas impostas por emissóes de GEE de outras pessoas, que advém, especialmente, de países ricos. Desta forma, foi aberta a caixa preta da complexidade de uma avaliação do bem-estar considerando aspectos do meio ambiente e permitindo analisar as heterogeneidades das pessoas e as diversidades ambientais, sociais e políticas que interagem na caracterização do bem-estar de uma pessoa.

As evidências analisadas demonstraram como as alteraçóes do clima constituem um risco latente para o retrocesso do desenvolvimento humano e ampliação das privaçóes humanas, com desproporcionais efeitos para países pobres e em desenvolvimento. Por um lado, os choques climáticos ameaçam em diferentes caminhos (direta e indiretamente) os funcionamentos e capacitaçóes das pessoas, o "fim em si mesmo" do desenvolvimento humano, com respeito à saúde, a educação, os valores culturais e as relaçóes sociais.

Por outro lado, os choques climáticos restringem o desenvolvimento humano ao afetar e limitar os meios e intitulamentos necessários para o sustento das pessoas, através da reduçáo da quantidade e qualidade da água, da produção agrícola, da alteração de atividades de pesca, redução de rendimentos econômicos, entre outras formas citadas. Os maiores impactos são em áreas rurais, as quais concentram maior proporção de pobres. Além disso, as pessoas pobres são limitadas no exercício de escolha do estilo de vida que valoram, pois são influenciadas em seu bem-estar por decisôes de emissão de GEE de outras pessoas. 
Considerando a complementaridade de cada componente do bemestar, o efeito da mudança climática sobre um componente, reduz a qualidade do outro e cada ciclo conjugado de impactos negativos, retrocede o bem-estar humano como um todo, e dessa forma, ampliam-se as privaçóes humanas e restringe-se o desenvolvimento humano.

Por último, foram considerados fatores de vulnerabilidade pré-existentes, que também se conjugam para definir o grau de impacto negativo sobre o bem-estar das pessoas. Assim sendo, foi visto que os choques climáticos podem afetar mais profundamente os seres humanos que vivem nas áreas geográficas de maior ocorrência de eventos extremos do clima, como a região dos trópicos e subtrópicos. De igual forma, o grau de impacto é mais severo, quando as pessoas dependem em maior proporçáo da agricultura e dos serviços dos ecossistemas, sendo estas as pessoas de áreas rurais e as pessoas pobres. Por último, foi verificado que os impactos mais profundos são e podem ser para aquelas pessoas que vivem em condiçôes já fragilizadas e privadas de bem-estar, interagindo com condiçôes de pobreza, desigualdade social, limitado acesso à água tratada e ao saneamento básico, recursos naturais mais degradados, precária infra-estrutura física, ampliando assim a privação dos mais pobres. Foi constatado que os países pobres e em desenvolvimento apresentam maior vulnerabilidade às alteraçōes climáticas e, em especial, há maior vulnerabilidade entre crianças e mulheres nesses países.

\section{Referências}

Abramovay, Ricardo (2010), Reduzir a desigualdade entre os individuos para combater o aquecimento global, Boletim da Sociedade Brasileira de Economia Ecológica, Edição Especial, núm. 23/24, Sociedade Brasileira de Economia Ecológica, Brasília.

Allison, Edward, Neil Adger, Marie-Caroline Badjeck, Katrina Brown, Declan Conway, Nick Dulvy, Ashley Halls, Allison Perry e John Reynolds (2005), Effects of climate change on the sustainability of capture and enhancement fisheries important to the poor: analysis of the vulnerability and adaptability of fisherfolk living in poverty. Project núm. R4778J, Final Technical Report, Fisheries Management Science Programme, Marine Resources Assessment Group Ltd (MRAG), Department for International Development (DFID), London. 
Anand, Sudhir e Amartya Sen (2000), "Human development and economic sustainability", World Development, 28 (12), Elsevier, Oxford, pp. 2029-2049.

Arnell, Niger (1999), "Climate change and global water resources", Global Environmental Change, 9 (1), Elsevier, Oxford, pp. 31-49.

Arnell, Niger (2004), "Climate change and global water resources: SRES emissions and socio economic scenarios", Global Environmental Change, 14 (1), Elsevier, Oxford, pp. 31-52.

Bagolin, Izete (2005), "Da renda às capacitaçôes: analisando e avaliando o desenvolvimento humano", tese doutorado, Programa de Pós Graduação em Economia, Faculdade de Ciências Econômicas, Universidade Federal do Rio Grande do Sul, Porto Alegre.

Barnett, Jon e Neil Adger (2007), "Climate change, human security and violent conflict”, Political Geography, 26 (6), Elsevier, Oxford, pp. 639-655.

Beniston, Martin, Franziska Keller e Stéphane Goyette (2003), "Snow pack in the Swiss Alps under changing climatic conditions: an empirical approach for climate impact studies", Theoretical Applied Climatology, 74 (1-2), Springer, Viena, pp. 19-31.

Berrittella, Maria, Andrea Biganoa, Roberto Roson e Richard Tol (2006), "A general equilibrium analysis of climate change impacts on tourism", Tourism Management, 27 (5), Elsevier, Oxford, pp. 913-924.

Black, Robert, Lindsay Allen, Zulfigar Bhutta, Laura Caulfield, Mercedes de Onis, Majid Ezzati, Colin Mathers e Juan Rivera (2008), "Maternal and child undernutrition: global and regional exposures and health consequences", The Lancet, 371 (9608), Elsevier, Oxford, pp. 243-260.

Chambers, Robert e Gordon Conway (1991), "Sustainable rural livelihoods: Practical concepts for the 21st Century", IDs Discussion Paper 296, Institute of Development Studies, Brighton.

Comim, Flávio, Izete Bagolin, Sabino da Silva Porto, Reisoli Bender Filho, Volnei Picolotto y Rodrigo Avila (2007), Indicadores de pobreza 
multidimensional e pobreza extrema para Porto Alegre, REDE URB-AL 10 (1), Ed Montevideo, Porto Alegre.

Confalonieri, Ulisses, Bettina Menne, Rais Akhtar, Kristie Ebi, Maria Hauengue, Sari Kovats, Boris Revich e Alistair Woodward (2007), "Human health", en Martin Parry, Osvaldo Canziani, Jean Palutikof, Paul Van Der Linden e Clair Hanson (eds.), Climate change 2007: Impacts, adaptation and vulnerability. Contribution of working group II to the Fourth Assessment Report of the Intergovernmental Panel on Climate Change, Cambridge University Press, Cambridge, pp. 391-431.

Dasgupta, Susmita, Benoit Laplante, Craig Meisner, David Wheeler e Jianping Yan (2007), "The impact of sea level rise on developing countries: A comparative analysis”, Policy Research Working Paper 4136, World Bank, Washington DC.

Elsasser, Hans e Rolf Bürki (2002), "Climate change as a threat to tourism in the Alps", Climate Research, vol. 20, Inter-Research Science Center, Oldendorf/Luhe, pp. 253-257.

Féres, José, Eustáquio Reis y Juliana Simões Speranza (2011), "Impacto das mudanças climáticas no setor agrícola brasileiro", em Ronaldo Seroa da Motta, Jorge Hargrave, Gustavo Luedemann e Maria Bernadete Sarmiento Gutierrez (eds.), Mudança do clima no Brasil: aspectos econômicos, sociais e regulatórios, Instituto de Pesquisa Econômica Aplicada, Brasília, pp. 299-309.

Fischer, Günther, Mahendra Shah y Harij Van Velthuizen (2002), Climate change and agricultural vulnerability, International Institute for Applied Systems Analysis, Remaprint, Viena.

Fischer, Günther, Francesco Tubiello, Harrij Van Velthuizen y David Wiberg (2007), "Climate change impacts on irrigation water requirements: Effects of mitigation, 1990-2080", Technological Forecasting Social Change, 74 (7), Elsevier, Oxford, pp. 1083-1107.

FAO (Food and Agriculture Organization of the United Nations) (2006), AQUASTAT database, <http://www.fao.org/ag/aquastat>, Atualização: 11 de junho de 2009, 15 de julho de 2009. 
Hansen, James, Maxx Dilley, Lisa Goddard, Esther Ebrahimian e Polly Erickser (2004), Climate variability and the millennium development goal hunger target, International Research Institute for Climate Prediction, IRI Technical Report núm. 04-04, The Earth Institute of Columbia University Palisades, New York.

Hemon, Denis e Eric Jougla (2004), "La canicule du mois d'aout 2003 en France", Revue d'Epidemiologie et de Sante Publique, 52 (1), Elsevier Masson, Francia, pp. 3-5.

Holland, Breena (2008), “Justice and the environment in Nussbaum's 'capabilities approach': Why sustainable ecological capacity is a meta-capability", Political Research Quarterly, 61 (2), Sage Publications, Inc, California, pp. 319-332.

IPCC (International Panel on Climate Change) (2007a), "Summary for Policymakers”, em Martin Parry, Osvaldo Canziani, Jean Palutikof, Paul Van Der Linden y Clair Hanson (eds.), Climate change 2007: Impacts, adaptation and vulnerability. Contribution of working group II to the Fourth Assessment Report of the Intergovernmental Panel on Climate Change, Cambridge University Press, Cambridge, pp. 7-22.

IPCC (International Panel on Climate Change) (2007b), "Summary for Policymakers”, em Susan Solomon, Dahe Qin, Martin Manning, Melinda Marquis, Kristen Averyt, Melinda Tignor, Henry Leroy Miller y Zhenlin Chen (eds.), Climate change 2007: The physical science basis. Contribution of working group I to the Fourth Assessment Report of the Intergovernmental Panel on Climate Change, Cambridge University Press, Cambridge and New York, pp. 2-18.

Kunii, Osamu, Seiichi Nakamura, Rashid Abdur e Susumu Wakai (2002), "The impact on health and risk factors of the diarrhea epidemics in the 1998 Bangladesh floods", Public Health, 116 (2), Elsevier, Oxford, pp. 68-74.

MA (Millennium Ecosystem Assessment) (2003), Ecosystems and human well-being: A framework for assessment, World Resources Institute, Island Press, Washington DC. 
MA (Millennium Ecosystem Assessment) (2005), Ecosystems and human well-being: Policy responses, vol, 3, World Resources Institute, Island Press, Washington DC.

Marengo, Jose, Carlos Nobre, Sin Chan Chou, Javier Tomasella, Gilvan Sampaio, Lincoln Alves, Guillermo Obregón, Wagner Soares, Richard Betts e Gillian Kay (2011), Riscos das mudanças climáticas no Brasil: análise conjunta Brasil-Reino unido sobre os impactos das mudanças climáticas e do desmatamento na Amazônia, Instituto Nacional de Pesquisas Espaciais (INPE), Met Office Hadley Centre (монс), Brasil, Reino Unido.

McMichael, Anthony, Diarmid Campbell-Lendrum, Carlos Corvalan, Kristie Ebi, Andrew Githeko, Joel Scheraga e Alistair Woodward (2003), Climate change and human health: Risk and responses, World Health Organization, Geneva.

Mendelsohn, Robert, Ariel Dinar e Larry Williams (2006), "The distributional impact of climate change on rich and poor countries", Environment and Development Economics, 11 (2), Cambridge University Press, Cambridge, pp. 159-178.

Mendelsohn, Robert, Alan Basist, Pradeep Kurukulasuriya e Ariel Dinar (2007), "Climate and rural income", Climatic Change, 81 (1), Springer, Netherlands, pp. 101-118.

Nussbaum, Martha (2003), "Capabilities as fundamental entitlements: Sen and social justice", Feminist Economics, 9 (2-3), RoutledgeTaylor and Francis Group, Oxford, pp. 33-59.

Nussbaum, Martha (2011), Creating capabilities: The human development approach, The Belknap Press of Harvard University Press, Cambridge, Massachusetts.

OMS-Unicef (Organização Mundial da Saúde y Fundo das Nações Unidas para a Infância) (2005), World Malaria Report 2005, World Health Organization, The United Nations Children's Fund, Geneva, New York.

Page, Edward (2007), "Intergenerational justice of what: Welfare, resources, or capabilities?”, Environmental Politics, 16 (3), Routledge-Taylor and Francis Group, Oxford, pp. 453-469. 
Parry, Martin, Cynthia Rosenzweig, Ana Iglesias, Günther Fischer e Matthew Livermore (1999), "Climate change and world food security: a new assessment", Global Environmental Change, 9 (1), Elsevier, Oxford, pp.51-68.

Perch-Nielsen, Sabine, Michele Bättig e Dieter Imboden (2008), "Exploring the link between climate change and migration", Climatic Change, 91 (3-4), Springer, Netherlands, pp. 375-393.

PNUd (Programa das Naçóes Unidas para o Desenvolvimento) (2006), Relatório de Desenvolvimento Humano 2006: A água para lá da escassez: poder, pobreza e a crise mundial da água, Programa das Naçôes Unidas para o Desenvolvimento, New York.

PNUD (Programa das Naçóes Unidas para o Desenvolvimento) (2007), Relatório de Desenvolvimento Humano 2007/2008: Combater as alteraçóes climáticas: Solidariedade humana num mundo dividido, Programa das Naçóes Unidas para o Desenvolvimento, New York.

Sen, Amartya (1985), Commodities and capabilities, North Holland, Amsterdam.

Sen, Amartya (2000), Desenvolvimento como liberdade, Companhia das Letras, São Paulo.

Sen, Amartya (2001), Desigualdade reexaminada, Record, Rio de Janeiro.

Sen, Amartya (2002), “¡Por qué la equidad en salud?”, Revista Panamericana de Salud Pública, 11 (5-6), Organización Panamericana de la Salud, Washington, pp. 302-309.

Stern, Nicholas (2007), The economics of climate change: The stern review, Cambridge University Press, Cambridge.

Thomas, Chris, Alison Cameron, Rhys Green, Michel Bakkenes, Linda Beaumont, Yvonne Collingham, Barend Erasmus, Marinez Ferreira de Siqueira, Alan Grainger, Lee Hannah, Lesley Hughes, Brian Huntley, Albert van Jaarsveld, Guy Midgley, Lera Miles, Miguel Ortega-Huerta, Townsend Peterson, Oliver Phillips e Stephen Williams (2004), "Extinction risk from climate change", Nature, 427 (6970), Nature Publishing Group, pp. 145-148. 
Todd, Graham (2003), "wто background paper on climate change and tourism", en World Tourism Organization (eds.), Climate change and tourism, Proceedings of the 1st International Conference on Climate Change and Tourism, World Tourism Organization, Tunisia, pp. 17-55.

Tol, Richard e Hadi Dowlatabadi (2001), "Vector-borne diseases, development \& climate change", Integrated Assessment, vol. 2, Kluwer Academic Publishers, Netherlands, pp.173-181.

UNICEF (Fundo das Naçóes Unidas para a Infância) (2008), Our climate, our children, our responsibility: The implications of climate change for the world's children, The United Nations Children's Fund, UK.

Van Lieshout, Michael, Sari Kovats, Matthew Livermore e Pim Martens (2004), "Climate change and malaria: analysis of the SREs climate and socio-economic scenarios", Global Environmental Change, 14 (1), Elsevier, Oxford, pp. 87-99.

Warren, Rachel, Nigel Arnell, Robert Nicholls, Peter Levy e Jeff Price (2006), Understanding the regional impacts of climate change: research report prepared for the Stern Review on the Economics of Climate Change, Tyndall Centre for Climate Change Research, Working Paper 90, University of East Anglia, Norwich.

World Wide Fund for Nature (2006), Living Planet Report 2006, wwF International, Gland, Switzerland.

Recibido: 18 de julio de 2010. Reenviado: 12 de octubre de 2011. Aceptado: 23 de febrero de 2012.

Esmeralda Correa-Macana. Doutoranda em Economia da Universidade Federal do Rio Grande do Sul, Brasil. Atualmente é professora da Faculdade de Economia da Pontifícia Universidade Católica do Rio Grande do Sul. Tem atuado como consultora do Programa das Naçóes Unidas para o Desenvolvimento no Brasil e no Panamá. Sua linha de pesquisa atual é desenvolvimento humano e abordagem das capacitaçóes. Ela tem apresentado trabalhos em diferentes eventos a nível nacional e internacional sobre o tema de desenvolvimento humano e meio ambiente como: "Qual a relação entre pobreza e meio ambiente? Evidências e reflexóes 
desde uma perspectiva multidimensional do bem-estar humano" em III Conferência Latino Americana e Caribenha sobre Abordagem das Capacitaçóes e Desenvolvimento Humano, Asociación Lationoamericana y del Caribe sobre Desarrollo Humano y el Enfoque de las Capabilidades Porto Alegre, Brasil (2010); em coautoria, "Impactos potenciais da mudança climática no desenvolvimento humano" em Anais do XXXVI Encontro Nacional de Economia, Associação Nacional dos Centros de Pós-graduação em Economia-ANPEC, Bahia da Salvador, Brasil (2008). Entre suas últimas publicaçóes em coautoria destacam-se: "Custos dos acidentes de trânsito com vítimas associados ao uso de álcool em Porto Alegre", em Flávio Pechansky, Paulina do Carmo Arruda Vieira Duarte e Raquel De Boni (orgs.), Uso de bebidas alcoólicas e outras drogas nas rodovias brasileiras e outros estudos, Secretaria Nacional de Políticas sobre Drogas, Porto Alegre, pp. 100-111 (2010).

Flávio Comim. Doutor em economia pela Universidade de Cambridge (1999). Atualmente é professor adjunto da Universidade Federal do Rio Grande do Sul e professor Afiliado da Universidade de Cambridge. Foi economista sênior do Programa das Naçôes Unidas para o Desenvolvimento no Brasil e pesquisador associado do Von Hugel Institute, St. Edmund's College, Universidade de Cambridge. Tem experiência na área de economia do desenvolvimento, com ênfase em economia da pobreza, desenvolvimento humano e meio ambiente. Ele tem publicaçóes sobre a abordagem das capacitaçóes, envolvendo recentemente a co-edição de livros com Cambridge University Press e Oxford University Press, assim como especiais ediçóes no Journal of Economic Methodology e Review of Political Economy. Entre suas últimas publicaçóes destacam-se: em coautoria, "The capability approach and research on children: Capability approach and children's issues" em Sabine Andresen, Isabel Diehm, Uwe Sander e Holger Ziegle (eds.), Children and the good life: New challenges for research on children, vol. 4 (2), Springer, London, New York, pp. 75-89 (2010); em coautoria "Poverty and environment links: an illustration from Africa", Journal of International Development, vol. 21 (3), John Wiley and Sons, Nova Jersey, pp. 447-469 (2009); em coautoria, Capabilities and happiness, Oxford University Press, Oxford (2009); em coautoria, The capability approach: Concepts, measures and applications, Cambridge University Press, Cambridge (2008); em coautoria, "Climate injustice and development: a capability perspective", Development, vol. 51, Palgrave Macmillan, Cambridge, pp. 344-349 (2008). 